\title{
In-situ observation of compression
}

\section{damage in a 3D braided carbon fiber}

\section{reinforced carbon and silicon carbide}

\section{(C/C-SiC) ceramic composite}

Short title: In-situ compression damage in a C/C-SiC composite

Fan Wan ${ }^{1,2}$, Shixiang Zhao ${ }^{2}$, Rongjun Liu ${ }^{1}$, Changrui Zhang ${ }^{1}$ and Thomas James Marrow ${ }^{2}$

1. Science and Technology on Advanced Ceramic Fibers and Composites Laboratory,

National University of Defense Technology, Changsha, 410073, China

2. Department of Materials,

University of Oxford, Oxford, OX1 3PH, UK

Corresponding Author: Thomas James Marrow,

Department of Materials, University of Oxford, Oxford, OX1 3PH, UK.

Tel: 01865 273938, Fax: 01865 273289,

Email: james.marrow@materials.ox.ac.uk 


\section{Abstract}

Deformation and mechanical damage in a 3-dimensional (3D) braided carbon fiber reinforced carbon and silicon carbide (C/C-SiC) ceramic composite, subjected to compressive loading, has been studied in situ by laboratory X-ray computed tomography. Dimensional change was measured and damage visualized by digital volume correlation analysis of tomographs. Cracks nucleated from defects within the fiber bundles and tended to propagate along the fiber bundle/matrix interface. For longitudinal compression, parallel to the fiber bundles, the initial elastic modulus decreased with increasing compressive strain while significant transverse tensile strains developed due to distributed cracking. For transverse compression, perpendicular to the fiber bundles, the compressive elastic modulus was effectively constant; the tensile strains developed along the fiber direction were small, whilst macroscopic fracture between the fiber bundles caused very large bulk tensile strain perpendicular to the loading. The observations suggest that the mechanical strength might be improved through control of pre-existing defects and application of stitch fibers in the transverse direction.

\section{Key Words}

C/C-SiC; Ceramic composite; Compression; Damage; X-ray Computed Tomography; Digital Volume Correlation 


\section{Introduction}

Carbon fiber reinforced carbon and silicon carbide composites (C/C-SiC) have favorable properties for long-term operation at elevated temperatures, including wear resistance, oxidation resistance and dimensional stability (Zhou et al., 2012; Fan et al., 2015; Chen et al., 2016). They are designed for aerospace (Krenkel \& Berndt, 2005) and tribological (Xiong et al., 2016) technologies and have potential applications for nuclear energy (Shih et al., 2013). There is interest to optimize their properties through control of the microstructure, and the mechanical properties of various $\mathrm{C} / \mathrm{C}-\mathrm{SiC}$ composites have been studied in tension (Chen et al., 2016), compression ( $\mathrm{Li}$ et al., 2015), bending (Wang et al., 2009; Park et al., 2008), shearing (Dongmei et al., 2007) and by indentation (Cui et al., 2011). However, these are usually macroscopic tests that provide limited information on the influence of microstructure on the mechanical response.

X-ray computed tomography $(\mathrm{XCT})$ provides three-dimensional observations of microstructure, and may be applied during mechanical testing. Since the initial studies of Guvenilir (Guvenilir et al., 1997), in situ XCT has been applied to a wide range of materials including trabecular bone (Bay et al., 1999), wood (Forsberg et al., 2008), gypsum (Bouterf et al., 2014), graphite (Marrow et al., 2016; Hodgkins et al., 2006), ceramic matrix composites (Gao et al., 2016; Arhatari et al., 2017) and polymer matrix composites (Garcea et al., 2017; Emerson et al., 2017; Bie et al., 2017). The relative deformations between tomographs can be measured by digital volume correlation (DVC), which is a volumetric extension of the digital image correlation (DIC) method. First demonstrated by Bay. (Bay et al., 1999), DVC analysis of XCT data allows the full-field displacements and strains (i.e. displacement field gradients) to be measured. Cracks cause discontinuities in the displacement field that are readily detected as localized strain features (Joyce et al., 2008), so DVC and XCT have been used to investigate the relationships between microstructure and mechanical damage in a range of materials that include graphite (Barhli et al., 2017), concrete (Yang et al., 2017), ceramics 
(Vertyagina et al., 2014) and ceramic composites (Saucedo-Mora et al., 2016), metallic alloys (Cai et al., 2016; Mostafavi et al., 2015, 2016; Steuwer et al., 2006; Réthoré et al., 2011) and porous compacts of particulates (Forsberg \& Siviour, 2009).

Composites are attractive materials for load-bearing structures in aeronautics and astronautics, but their mechanical properties are quite sensitive to their architectures. The 5-directional braided structure composites ( $\mathrm{Li}$ et al., 2009; Zhang et al., 2015) are a development of 4-directional structures (i.e. with four groups of parallel yarns that form two sets of parallel planes and intersect orthogonally). In the 5-directional structure, uniaxial reinforced yarns are added along the braiding direction, and microstructure variables include the braiding pitch width, length and angle. Previous works have focused on polymer (epoxy) matrix composites (Zhang et al., 2015; Li et al., 2012; Deng et al., 2017) and although numerical models of the 5-directional braided composite architecture have been generally successful in the simulation of mechanical properties, the prediction of tensile and compressive strength remains challenging. This is particularly important in ceramic composites, which have brittle matrices that can fail at small strains.

Previous studies in woven ceramic composites have demonstrated some of the insights that can be obtained by combined modelling and in situ experimental observation of damage development (Saucedo-Mora et al., 2017). Consequently, in this work the microstructure and patterns of damage distribution in a 3D 5-directional braided ceramic composite (C/C-SiC) were observed by $\mathrm{XCT}$, and DVC was used to visualize the development of cracking and also to measure the effects of damage on the dimensional change of the composite. The objectives were to observe the mechanisms of damage development, and also to investigate whether the dimensional change under load could be measured. Such observations would provide inputs and validation data for future modelling efforts. 


\section{Materials and Methods}

\section{Materials}

The composite studied in this work was fabricated by Gaseous Silicon Infiltration (GSI) at the laboratory of Science and Technology on Advanced Ceramic Fibers and Composites at the National University of Defense Technology (China). The Composites Institute of Tianjing Technology University (China) provided the $\mathrm{T}-300$ carbon fiber for the $\mathrm{C} / \mathrm{C}$ perform, which was fabricated by pyrolytic carbon deposition onto a braided carbon fiber structure by chemical vapour deposition (CVD) at $960^{\circ} \mathrm{C}$; propylene and argon were used as precursor and carrier diluting gases respectively, and the final bulk density of the $\mathrm{C} / \mathrm{C}$ preform was $1.4 \mathrm{~g} / \mathrm{cm}^{3}$. The 5-directional preform had a braiding pitch width of 2.1 to $2.2 \mathrm{~mm}$, a braiding pitch length of 4 to $6 \mathrm{~mm}$ and a fiber volume fraction of $\sim 50 \%$. This was reacted with gaseous silicon at $1600^{\circ} \mathrm{C}$ to produce $\mathrm{C} / \mathrm{C}$-SiC composite with a density of $2.2 \mathrm{~g} / \mathrm{cm}^{3}$. A block of this material, measuring $120 \mathrm{~mm} \times 50 \mathrm{~mm} \times 5.2 \mathrm{~mm}$, was sliced into $120 \mathrm{~mm}$ long strips by water-jet cutting, from which the test specimens were cut using a water-cooled diamond saw (0.6 mm blade width).

\section{Compression Testing}

Compression tests were done between flat stainless steel anvils using a Deben CT5000 loading rig (5 kN load capacity) mounted within an Xradia Versa 510 X-ray microscope, which was operated at $80 \mathrm{keV}$ energy and $7 \mathrm{~W}$ power. Each tomograph was obtained from 1000 projections over a $360^{\circ}$ rotation, with an exposure time of $4 \mathrm{~s}$ per projection. The voxel size was $11.5 \mu \mathrm{m}$ and each scan took about 2 hours and 40 minutes. The tomographs were reconstructed using the instrument software, and were visualized using Avizo 9.3.0 (a sandbox filter with a median value 1.0 was applied). 
Both longitudinal and transverse compression tests were done; in longitudinal compression, the load direction was parallel to the fiber bundles. The specimen dimensions $(x \times y \times z)$ for the longitudinal and transverse tests were $5.2 \mathrm{~mm} \times 4.6 \mathrm{~mm} \times 10.7 \mathrm{~mm}$ and $5.8 \mathrm{~mm} \times 5.2 \mathrm{~mm} \times 11.0 \mathrm{~mm}$, respectively with the load applied along the $z$-axis. Each sample was observed at a pre-load of $20 \mathrm{~N}$, and then at progressively higher loads with crosshead displacement control $(0.5 \mathrm{~mm} / \mathrm{min})$ of the loading rig.

\section{Results}

\section{Material Characterization}

Tomographic reconstructions of the tested specimens are shown in Figure 1. The reconstructed volume is in the central part of each specimen. Due to shadowing from the loading anvils, the observed volume had a height of $7.5 \mathrm{~mm}$ and $7.9 \mathrm{~mm}$ for the longitudinal and transverse specimens respectively. The microstructure directions ( $\mathrm{L}$, longitudinal; $\mathrm{W}$, width; $\mathrm{T}$, transverse) are defined in relation to the loading and tomography coordinate space $(x, y, z)$.

Orthogonal sections of a tomograph of the longitudinal specimen are shown in Figure 2a. Its segmentation into fibers, matrix and pores, using their relative X-ray attenuation (i.e. grey levels), is shown in Figure 2b; green represents fiber, yellow represents matrix, and red represents pores. The regions between the fibers are mostly filled with matrix, and both high aspect ratio and low aspect ratio pores are observed. The high aspect ratio intra-bundle pores are aligned along the fiber bundle length, while the low aspect ratio pores are distributed in the matrix. Volume visualizations of the porosity and matrix (Figure 2c and Figure 2d) show the alignment of the high aspect ratio pores and the continuous structure of the matrix. The area fractions of pores and matrix were measured along the orthogonal directions, in a series of $2 \mathrm{D}$ slices of the tomograph, using simple threshold segmentation in the Image J software (Schneider et al., 2012). Almost constant fractions of pores, 
matrix and fiber are observed in the $x y$ sections (i.e. along the L direction that is parallel to the fiber bundles) (Figure 2e). The weave of the fiber bundles causes large and correlated fluctuations in both the $\mathrm{W}$ and $\mathrm{T}$ directions for the matrix/fiber fractions in the $x z$ (Figure $2 \mathrm{f}$ ) and $y z$ sections (Figure $2 \mathrm{~g}$ ), respectively, with a periodicity of $1 \mathrm{~mm}$. The total porosity detected was $3.5 \%$, with a matrix volume fraction of $37.8 \%$. This compares quite well with a component analysis data of th material, following the Archimedes and gravimetric method of Nie (Nie et al., 2010), which measured 4.9\% porosity $(2.8 \%$ open and $2.1 \%$ closed), $53 \%$ carbon fibers and $42.1 \%$ matrix volume fraction.

The load-crosshead displacement data (Figure 3) show that the longitudinal compression sample did not fail completely within the $5 \mathrm{kN}$ load capacity of the rig (i.e. $209 \mathrm{MPa}$ compressive stress), while the transverse specimen fractured at $3.8 \mathrm{kN}$ (i.e. $127 \mathrm{MPa}$ compressive stress). Circles mark the loads at which tomographs were recorded; a load relaxation of up to $300 \mathrm{~N}$ occurred during each $\operatorname{scan}^{1}$.

Example tomographs of the damaged specimens are shown in Figure 4. The longitudinal compressed specimen, observed at its maximum load $(5000 \mathrm{~N})$, is visualized in Figure 4a, with orthogonal sections presented in the LW (Figure 4b) and LT (Figure 4c) planes. It developed significant damage to one side. The transverse compression specimen developed a significant diagonal crack when it failed. This is shown in Figure 4d, with orthogonal sections (TL and WL planes) in Figure 4e and Figure 4f. The sections of the longitudinal specimen (Figure $4 \mathrm{~b}$ and Figure 4c) show that cracks propagated mostly along the fiber bundle interfaces. In the transverse specimen

\footnotetext{
${ }^{1}$ The relaxation at $3000 \mathrm{~N}$ in the transverse test occurred due to a manual pause in the loading. No tomography scan was obtained at this load.
} 
(Figure $4 \mathrm{e}$ and Figure 4f), significant damage from multiple fiber breakages and matrix fragmentation is observed only near the main diagonal crack; less damage is visible remote from this.

The localized nature of the damage is shown for the longitudinal compressed specimen in Figure 5a and $\mathrm{b}$, which compares the same horizontal $x y$ section (WT plane) of tomographs recorded at $20 \mathrm{~N}$ and $5000 \mathrm{~N}$. Cracks clearly existed within the fiber bundles before loading at $20 \mathrm{~N}$ (Figure 5a), and by the final loading stage, these had extended beyond the fiber bundles (Figure 5c). This is illustrated by examining the progressive development of cracks in $3 \mathrm{D}$, using the two examples that are identified in Figure 5b. The cracks are visualized as solid features (red), obtained by image segmentation via a greyscale threshold, and the boundaries of the fiber bundles have been manually outlined (in yellow) in the $x y$ plane at intervals separated by $\sim 100 \mu \mathrm{m}$. The development of cracks at a single fiber bundle is shown in Figure 6: initially the crack existed inside the fiber bundle; but as the load increased this intra-bundle crack extended outside the bundle boundary. The development of damage in three fiber bundles is seen in Figure 7, which shows that the cracks coalesced with increasing load and propagated along the interface between the fiber bundle and matrix.

For transverse compression, Figure 8 shows sections in the same vertical $y z$ (TW) plane of successive tomography observations. Vertical cracking, which is identified within the dashed white box in Figure 8a to d, propagated parallel to the TL plane prior to the appearance of the inclined crack (Figure 8e), which occurred at the final failure. The tomograph in Figure 8e was obtained after the specimen had been removed from the loading rig; it shows a vertical section of the whole specimen, and the white dotted box outlines the smaller region that was observed in situ during loading. The development of the vertical cracking (within the dashed box) is visualized in 3D in Figure 9 at $20 \mathrm{~N}, 1500 \mathrm{~N}$ and $2000 \mathrm{~N}$ (preload, $50 \mathrm{MPa}$ and $66 \mathrm{MPa}$ ); the cracks are threshold segmented (red) and five fiber bundles have been outlined (yellow) in the $y z$ plane at intervals of 100 
$\mu \mathrm{m}$. Cracking developed mainly along the interfaces between the fiber bundles and matrix, similar to the longitudinal specimen.

\section{Digital Volume Correlation Analysis}

A digital volume correlation (DVC) analysis was applied to the tomographs of both the longitudinal and transverse compressed samples. The LaVision Davis software was used, with the initial tomograph under $20 \mathrm{~N}$ pre-load as the reference. A small subset size $(12 \times 12 \times 12$ voxels, $75 \%$ overlap, 2 passes) was applied to achieve high spatial resolution in the mapping of the displacement field. Examples of the displacements within each specimen at the maximum load are shown in Figure 10. The origin for the relative displacements was selected by applying a uniform rigid body displacement, with no rotation correction, and is labeled in each volume. The dimensions of the reported DVC data are $4.865 \mathrm{~mm} \times 4.106 \mathrm{~mm} \times 7.038 \mathrm{~mm}$ for the longitudinal specimen and 5.175 $\mathrm{mm} \times 4.520 \mathrm{~mm} \times 7.418 \mathrm{~mm}$ for the transverse specimen, after cropping to remove displacement vectors calculated from subsets that approached the edges of tomographed volume; erroneous pseudo-strains may be obtained by image correlation (Poissant \& Barthelat, 2010) at such discontinuities.

The 3D displacement fields are influenced by the microstructure (e.g. Figure 10c and e), and the effects of the vertical crack in the transverse loaded specimen are obvious (e.g. Figure 10f). To quantify the bulk dimensional changes, the net displacements across each volume were calculated from the relative displacements between points on opposing surfaces. The average strains were then obtained relative to the initial dimensions. For the longitudinal specimen, the strains increased nonlinearly with increasing stress (Figure 11a). The error bar reports the standard deviation of the set of $n$ measurements made between opposing points, where for instance $n=24600,29110$ and 17040 for the $y z, x z, x y$ surfaces of the longitudinal compressed sample. This standard deviation increased significantly as the load increased, due to the heterogeneity of the displacement field that is apparent 
in Figure 10. The compressive elastic modulus was estimated from the change between successive observations of the average axial $\varepsilon_{z}$ strain with the change in compressive stress. The modulus in the L direction, obtained up to a load of $1500 \mathrm{~N}(63 \mathrm{MPa})$, was approximately $160 \mathrm{GPa}$ and decreased with increasing compressive stress (Figure 11b). The transversely compressed specimen shows a more linear relation between the average compressive strain and stress (Figure 11a). The compressive modulus in the $\mathrm{T}$ direction was approximately $20 \mathrm{GPa}$, and did not decrease significantly with increasing stress (Figure 11b).

The average orthogonal strains $\left(\varepsilon_{x}, \varepsilon_{y}\right)$ that developed in response to the average axial strains $\left(\varepsilon_{z}\right)$ are summarized in Figure 11c for both the longitudinal and transverse specimens. For the transversely compressed specimen, there was very little strain $\left(\varepsilon_{x}<0.05 \%\right)$ parallel to the longitudinal (L) direction of the fiber bundles (Figure 1b). A quite significant strain ( $\varepsilon_{y}$ up to $\sim 3 \%$ ) evolved in the W direction (Figure 1b) due to the vertical crack in TL plane (Figure 8) that also caused a significant volume increase (Figure 11d). Loaded along the fiber bundle direction, the longitudinally compressed specimen expanded similarly in the $\mathrm{W}$ (i.e. $\varepsilon_{y}$ ) and $\mathrm{T}$ directions (i.e. $\varepsilon_{x}$ ), with a volume expansion that increased linearly with applied strain (Figure 11d).

The damage within the microstructure is quite difficult to resolve, as there is little attenuation contrast in tomographs when the crack opening is small compared to the voxel size (Mostafavi et al., 2013). However, DVC analysis can aid crack detection (Yang et al., 2017; Vertyagina et al., 2014; Saucedo-Mora et al., 2016). This is illustrated in Figure 12a and b, which compare a cross-section (TW plane) of the longitudinally loaded specimen (at $5000 \mathrm{~N}$ ) with the equivalent section of the maximum principal 3D strain field, which is calculated from the local gradients of the displacement field. The variation with load of the longitudinal axial compression strain, across the sample, is summarized in Figure 12c. The strains were averaged along the $x$-direction, and increase in magnitude with position in the $y$-direction with a concentration towards one edge. Cracks that are 
observed in the tomograph are clearly associated with the largest local strains, and these are concentrated towards the specimen edge that experienced the largest axial compressive strain. Localized strains are also observed within the fiber bundles and at their interfaces where cracks cannot be resolved in the tomograph.

3D visualizations of the development of strain with load are presented in Figure 13 for both the longitudinally and transverse loaded specimens. The damage near to the edge of the longitudinal specimen (Figure 5b), which experienced the largest axial compressive strain (Figure 12c), is clearly visible in Figure 13a to d. The propagation of the vertical crack in the transverse specimen can also be observed (Figure 13e to f).

\section{Discussion}

The anisotropy of the braided microstructure is clearly observed in the tomographs and the quantitative analysis of the fiber/matrix distributions (Figure 2). In the longitudinal direction, the average fiber/matrix ratio is constant (i.e. $2 / 3$, neglecting the $\sim 5 \%$ porosity), and the periodic variation of matrix to fiber ratio in the $\mathrm{W}$ and $\mathrm{T}$ directions records the same wavelength of $\sim 1 \mathrm{~mm}$. This is consistent with the braiding pitch of $\sim 2 \mathrm{~mm}$, which is the unit cell dimension of the alternating weave directions ( $\mathrm{Li}$ et al., 2009). $\mathrm{W}$ and $\mathrm{T}$ are equivalent directions in the braided architecture, and should have equivalent properties. The non-linear relationship between the load and crosshead displacement at low loads in the longitudinal orientation (Figure 3a) might be attributed to compliance of the load train. However, it is not observed in the transverse direction for similar loads and specimen dimensions (Figure 3b). Measurements of the elastic modulus in this region have not been attempted using the crosshead displacement data, as these cannot be regarded as reliable due to the high stiffness of the specimen compared to the tomography loading rig. Nonetheless, it is interesting to note that similar non-linear behavior has been reported in longitudinal 
compression tests of braided composites (Wang et al., 2006), and this might be due to weaker lateral restraint in this orientation.

The DVC measurements of the dimensional change under load, obtained above the non-linear region, allow the longitudinal and transverse elastic moduli to be measured (Figure 11b). Although there is a gradient of axial strain across the longitudinal specimen in the $\mathrm{W}$ direction (e.g. Figure 12c), the average strains are quite representative of the strains in the bulk of the specimen. The apparent decrease in the longitudinal modulus with increasing axial strain is a consequence of mechanical damage (Figure 5), arising from the tensile Poisson strains. These cracks increase the compliance orthogonal to the applied load, with an effect that depends on the degree of constraint (Bažant \& Xiang, 1997), which is affected by specimen size and geometry. This is classical behaviour for brittle materials tested in compression (Ashby \& Cooksley), 1986), including reinforced concretes(Hsu, 1996). The significant effect of compressive strain on the specimen volumes (Figure 11d) indicates the low constraint of these tests. This constraint is affected by the anisotropy of the microstructure, as illustrated by the difference between $\varepsilon_{W}$ and $\varepsilon_{L}$ in the transverse compression test (Figure 11c). The mechanical response of small specimen tests therefore depends on the composite architecture, the initial properties of its constituents and the development of damage.

Dimensional change data, such as obtained by DVC and tomography, can be used with image-based models (Saucedo-Mora et al., 2017) to extract the properties of the microstructure constituents and local criteria for damage development. That is beyond the scope of this work, but a simple consideration may be done. The high longitudinal compressive modulus ( $160 \mathrm{GPa})$ is due to the axial stiffness of the fibres and continuous ceramic matrix, although a simple Voigt model suggests that this is still relatively low compared to the expected Young's moduli (Miyagawa et al., 2006) of the T300 fiber $(\sim 230 \mathrm{GPa})$, and typical properties $(\sim 200 \mathrm{GPa})$ of $\mathrm{SiC}$ produced by the GSI process (Huang et al., 2016). However, the longitudinal modulus reduces with compression (Figure 11), so 
the value measured at $0.04 \%$ strain is expected to under-represent the initial elastic properties, and is also expected to be reduced by the misalignment of loading (i.e. Figure 12c). The periodicity of fiber and matrix (Figure 2) suggests a simple Reuss model for the transverse stiffness may be considered, which is dominated by the most compliant phase. The measured transverse stiffness of $20 \mathrm{GPa}$, which is unaffected by strain, is then consistent with literature data (Miyagawa et al., 2006) for the transverse Young's moduli of T300 carbon fibers, which is of the order of 5-14 GPa (the manufacturer's value is nominally $8 \mathrm{GPa}$ ). This gives confidence in the measurement of elastic deformation by the DVC analysis of tomographs, and future studies with tomographs obtained more frequently could examine the effects of the braided composite structure on the apparent linear/nonlinear difference in behavior with orientation that is observed at low loads (i.e. Figure 3).

In addition to dimensional change measurement, the DVC analysis of tomographs provides information on the quality of alignment of the mechanical test. This is particularly important for small specimen tests of stiff materials. This is clear in the longitudinal specimen, in which the axial displacement field (Figure 10c) and axial strain variation (Figure 12c) show that the loading is not quite uniform. The observed variation of compressive axial strain across the specimen, which had nominally parallel surfaces, is of the magnitude that would be caused by a $0.2^{\circ}$ non-parallel misalignment between the specimen surfaces and loading anvils, and is observable due to the precision of the DVC analysis. The DVC data can also be used to observe the crack opening displacements. This is most obvious in Figure 10f, which shows that the vertical crack in the TL plane opens normally, with negligible shear. The sensitivity of DVC improves the detection of cracks, (e.g. Figure 12b and Figure 13), since these introduce discontinuities and steep gradients in the displacement field that can be visualized as significant local strains. Care should be taken in quantitative analysis of such strains, as, similarly to DIC, pseudo strains can be obtained from the large displacements that may be erroneously calculated close to the surfaces of open cracks (e.g. Figure 10e). Nonetheless, the DVC analysis augments the detection of damage development and 
reveals cracks that cannot be detected by tomography alone. In principle, it should be possible to quantify the volume and numbers of cracks that are detected using the DVC analysis, and relate this to the observed dimensional changes to quantitatively verify that these are caused by cracking. However, such measures are subject to significant errors due to the need for a subjective strain threshold that would separate the strains from the displacement field discontinuities that are caused by cracks, and those that arise from random errors in the displacement measurement. The subset analysis to measure the displacements also leads to a decreased resolution of the DVC data, which then prevents reliable measurement of the volume of the detected cracks. The displacement field may, however, be used to inform advanced post-processing of the tomographs to improve the image contrast of fine cracks (Nguyen et al., 2016), and this is planned for future studies.

The observation that pre-existing defects are the origins of cracks that propagate to damage the material (see Figure 6a, Figure 7a, and Figure 5a) is significant. These propagate from within the fiber bundles and coalesce in the brittle matrix. This suggests that the mechanical strength might be improved through control of these pre-existing defects. The clear effect of constraint on damage development also suggests that stitch fibers (Xie et al., 2015; Nie et al., 2008), applied in the transverse directions, might resist cracking and lead to improved strength.

\section{Conclusions}

In situ observations by computed X-ray tomography during compressive loading of a 3-dimensional braided carbon fiber reinforced carbon and silicon carbide $(\mathrm{C} / \mathrm{C}-\mathrm{SiC})$ ceramic composite show that cracks initiate from initial defects within the fiber bundles and tended to propagate along the fiber bundle/matrix interface. Consequently, the composite has a tendency for fracture parallel to the longitudinally aligned fiber bundles. Cracking and dimensional change can be studied with 
increased sensitivity by digital volume correlation analysis of tomographs to measure the full field displacements.

\section{Acknowledgements}

We acknowledge EPSRC Grant EP/M02833X/1 “University of Oxford: experimental equipment upgrade", which supported the Xradia Versa 510 microscope and facilities for data analysis and visualization. The research is part of the Project 51102282 supported by the National Natural Science Foundation of China, and the Research Project JC14-01-01 of National University of Defense Technology. The work was conducted at Oxford University, with China Scholarship Council support for Wan Fan as a recognized student. 


\section{References}

Arhatari, B. D., Zonneveldt, M., Thornton, J. \& AbBey, B. (2017). Local Structural Damage Evaluation of a C/C-SiC Ceramic Matrix Composite. Microscopy and Microanalysis 23, 518526.

Ashby, M. F. \& CoOKSLEY), S. D. H. (NÉE (1986). The failure of brittle solids containing small cracks under compressive stress states. Acta Metallurgica 34, 497-510.

Barhli, S. M., Saucedo-Mora, L., Jordan, M. S. L., Cinar, A. F., Reinhard, C., Mostafavi, M. \& MARrow, T. J. (2017). Synchrotron X-ray characterization of crack strain fields in polygranular graphite. Carbon 124, 357-371.

BAy, B. K., Smith, T. S., Fyhrie, D. P. \& SAAD, M. (1999). Digital volume correlation: Threedimensional strain mapping using x-ray tomography. Experimental Mechanics 39, 217-226.

BAŽANT, Z. P. \& XIANG, Y. (1997). Size effect in compression fracture: Splitting crack band propagation. Journal of Engineering Mechanics 123, 162-172.

Bie, B. X., Huang, J. Y., Fan, D., Sun, T., FezzaA, K., Xiao, X. H., Qi, M. L. \& Luo, S. N. (2017). Orientation-dependent tensile deformation and damage of a T700 carbon fiber/epoxy composite: A synchrotron-based study. Carbon 121, 127-133.

Bouterf, A., Roux, S., Hild, F., Adrien, J., Maire, E. \& Meille, S. (2014). Digital volume correlation applied to X-ray tomography images from spherical indentation tests on lightweight gypsum. Strain 50, 444-453.

Cai, B., Lee, P. D., Karagadde, S., Marrow, T. J. \& Connolley, T. (2016). Time-resolved synchrotron tomographic quantification of deformation during indentation of an equiaxed semisolid granular alloy. Acta Materialia 105, 338-346.

Chen, Z., Fang, G., Xie, J. \& Liang, J. (2016). Experimental study of high-temperature tensile mechanical properties of 3D needled C/C-SiC composites. Materials Science and Engineering: A 654, 271-277.

CUI, Y. Y., BAI, R. C., LI, A. J., REN, M. S. \& Sun, J. L. (2011). Microstructure and micromechanical property of C/C-SiC composites. Advanced Materials Research 299-300, 238-241.

Deng, J., Zhou, G., Ji, L. \& WAng, X. (2017). Mechanical Behaviour of 3D Multi-layer Braided Composites: Experimental, Numerical and Theoretical Study. Applied Composite Materials 24, $1509-1523$.

Dongmei, Z., Hongna, D., FA, L. \& Wancheng, Z. (2007). Preparation and mechanical properties of C/C-SiC composites. Materials Science Forum 546-549, 1501-1504.

Emerson, M. J., Jespersen, K. M., Dahl, A. B., Conradsen, K. \& Mikkelsen, L. P. (2017). Individual fibre segmentation from 3D X-ray computed tomography for characterising the fibre orientation in unidirectional composite materials. Composites Part A: Applied Science and 
Manufacturing 97, 83-92.

Fan, X., Yin, X., CaO, X., Chen, L., Cheng, L. \& Zhang, L. (2015). Improvement of the mechanical and thermophysical properties of $\mathrm{C} / \mathrm{SiC}$ composites fabricated by liquid silicon infiltration. Composites Science and Technology 115, 21-27.

Forsberg, F., Mooser, R., Arnold, M., HACK, E. \& Wyss, P. (2008). 3D micro-scale deformations of wood in bending: synchrotron radiation $\mu \mathrm{CT}$ data analyzed with digital volume correlation. Journal of structural biology 164, 255-62.

ForsberG, F. \& Siviour, C. R. (2009). 3D deformation and strain analysis in compacted sugar using $\mathrm{X}$-ray microtomography and digital volume correlation. Measurement Science and Technology 20.

GaO, Y., Wang, Y., Yang, X., LiU, M., Xia, H., Huai, P. \& Zhou, X. (2016). Synchrotron X-ray tomographic characterization of CVI engineered 2D-woven and 3D-braided $\mathrm{SiCf} / \mathrm{SiC}$ composites. Ceramics International 42, 17137-17147.

Garcea, S. C., Sinclair, I., Spearing, S. M. \& Withers, P. J. (2017). Mapping fibre failure in situ in carbon fibre reinforced polymers by fast synchrotron X-ray computed tomography. Composites Science and Technology 149, 81-89.

Guvenilir, A., Breunig, T. M., Kinney, J. H. \& Stock, S. R. (1997). Direct observation of crack opening as a function of applied load in the interior of a notched tensile sample of Al Li 2090. Acta Materialia 45, 1977-1987.

Hodgkins, A., Marrow, T. J., Mummery, P., Marsden, B. \& FoK, A. (2006). X-ray tomography observation of crack propagation in nuclear graphite. Materials Science and Technology 22, 1045-1051.

Hsu, T. T. C. (1996). Toward a unified nomenclature for reinforced-concrete theory. Journal of Structural Engineering 122, 275-283.

Huang, L., LiU, R., WAng, Y., Zhang, C., Long, X. \& CAO, Y. (2016). Fabrication and properties of dense silicon carbide ceramic via gel-casting and gas silicon infiltration. Ceramics International 42, 18547-18553.

Joyce, M. R., Marrow, T. J., Mummery, P. \& Marsden, B. J. (2008). Observation of microstructure deformation and damage in nuclear graphite. Engineering Fracture Mechanics 75, 3633-3645.

Krenkel, W. \& Berndt, F. (2005). C/C-SiC composites for space applications and advanced friction systems. Materials Science and Engineering: A 412, 177-181.

LI, D. -S., LU, Z. -X., CHEN, L. \& LI, J. -L. (2009). Microstructure and mechanical properties of threedimensional five-directional braided composites. International Journal of Solids and Structures 46, 3422-3432.

LI, D., LuO, G., YaO, Q., JiAnG, N. \& JiANG, L. (2015). High temperature compression properties and failure mechanism of 3D needle-punched carbon/carbon composites. Materials Science and 
Engineering: A 621, 105-110.

LI, J.-C., CHEN, L., ZHANG, Y.-F. \& PAN, N. (2012). Microstructure and finite element analysis of 3D five-directional braided composites. Journal of Reinforced Plastics and Composites 31, 107115.

Marrow, T. J., Liu, D., Barhli, S. M., Saucedo-Mora, L., Vertyagina, Y., Collins, D. M., Reinhard, C., Kabra, S., Flewitt, P. E. J. \& SMith, D. J. (2016). In situ measurement of the strains within a mechanically loaded polygranular graphite. Carbon 96, 285-302.

Miyagawa, H., Mase, T., Sato, C., Drown, E., Drzal, L. T. \& Ikegami, K. (2006). Comparison of experimental and theoretical transverse elastic modulus of carbon fibers. Carbon 44, 20022008.

Mostafavi, M., Bradley, R., Armstrong, D. E. J. \& Marrow, T. J. (2016). Quantifying yield behaviour in metals by X-ray nanotomography. Scientific Reports 6, 34346.

Mostafavi, M., Collins, D. M., Cai, B., Bradley, R., Atwood, R. C., Reinhard, C., Jiang, X., GALANO, M., LEE, P. D. \& MARROW, T. J. (2015). Yield behavior beneath hardness indentations in ductile metals, measured by three-dimensional computed X-ray tomography and digital volume correlation. Acta Materialia 82, 468-482.

Mostafavi, M., McDonald, S. A., Mummery, P. M. \& Marrow, T. J. (2013). Observation and quantification of three-dimensional crack propagation in poly-granular graphite. Engineering Fracture Mechanics 110, 410-420.

Nguyen, T. T., Yvonnet, J., Bornert, M. \& Chateau, C. (2016). Initiation and propagation of complex 3D networks of cracks in heterogeneous quasi-brittle materials: Direct comparison between in situ testing-microCT experiments and phase field simulations. Journal of the $\begin{array}{lllll}\text { Mechanics and Physics of 320-350. } & \text { Solids }\end{array}$ http://www.sciencedirect.com/science/article/pii/S0022509616302563.

Nie, J., Xu, Y., Zhang, L., Fan, S., Xu, F., Cheng, L., Ma, J. \& Yin, X. (2010). Microstructure, thermophysical, and ablative performances of a 3D needled $\mathrm{C} / \mathrm{C}-\mathrm{SiC}$ composite. International Journal of Applied Ceramic Technology 7, 197-206.

Nie, J., Xu, Y., Zhang, L., Yin, X., Cheng, L. \& MA, J. (2008). Effect of stitch spacing on mechanical properties of carbon/silicon carbide composites. Composites Science and Technology 68, 2425-2432.

Park, H. S., Jang, J. J., LeE, K. H., Lim, K. H., PARK, S. B., Kim, Y. C. \& Hong, S. H. (2008). Effects of microstructure on flexural strength of biomorphic $\mathrm{C} / \mathrm{SiC}$ composites. International Journal of Fracture 151, 233-245.

Poissant, J. \& BARthelat, F. (2010). A novel 'subset splitting' procedure for digital image correlation on discontinuous displacement fields. Experimental Mechanics 50, 353-364.

Réthoré, J., Limodin, N., Buffière, J.-Y., Hild, F., Ludwig, W. \& RouX, S. (2011). Digital volume correlation analyses of synchrotron tomographic images. Journal of Strain Analysis for Engineering Design 46, 683-695. 
Saucedo-Mora, L., Lowe, T., Zhao, S., Lee, P. D., Mummery, P. M. \& Marrow, T. J. (2016). In situ observation of mechanical damage within a $\mathrm{SiC}-\mathrm{SiC}$ ceramic matrix composite. Journal of Nuclear Materials 481, 13-23.

Saucedo-Mora, L., Zou, C., Lowe, T. \& Marrow, T. J. (2017). Three-dimensional measurement and cohesive element modelling of deformation and damage in a 2.5-dimensional woven ceramic matrix composite. Fatigue \& Fracture of Engineering Materials \& Structures 40, 683695.

Schneider, C. A., RAsband, W. S. \& Eliceiri, K. W. (2012). NIH Image to ImageJ: 25 years of image analysis. Nature Methods 9, 671.

Shin, C., Katoh, Y., Snead, L. L. \& Steinbeck, J. (2013). The effect of neutron irradiation on the mechanical properties of C/SiC composites. Journal of Nuclear Materials 439, 192-201.

Steuwer, A., Edwards, L., Pratihar, S., Ganguly, S., Peel, M., Fitzpatrick, M. E., Marrow, T. J., Withers, P. J., Sinclair, I., Singh, K. D., GaO, N., Buslaps, T. \& Buffière, J.-Y. (2006). In situ analysis of cracks in structural materials using synchrotron X-ray tomography and diffraction. Nuclear Instruments and Methods in Physics Research Section B: Beam Interactions with Materials and Atoms 246, 217-225.

Vertyagina, Y., Mostafavi, M., Reinhard, C., Atwood, R. \& Marrow, T. J. (2014). In situ quantitative three-dimensional characterisation of sub-indentation cracking in polycrystalline alumina. Journal of the European Ceramic Society 34, 3127-3232.

Wang, B., JiaO, G. Q., Chang, Y. J. \& PAN, W. G. (2006). Shear and compress experimental study on 3-d braided C/Sic composites (in Chinese). Journal of Aeronautical Materials 26, 64-67.

WANG, J., Lin, M., XU, Z., Zhang, Y., ShI, Z., QIAN, J., QIAO, G. \& Jin, Z. (2009). Microstructure and mechanical properties of $\mathrm{C} / \mathrm{C}-\mathrm{SiC}$ composites fabricated by a rapid processing method. Journal of the European Ceramic Society 29, 3091-3097.

Xie, J., Liang, J., Fang, G. \& Chen, Z. (2015). Effect of needling parameters on the effective properties of 3D needled C/C-SiC composites. Composites Science and Technology 117, 69-77.

Xiong, C., Li, T., Zhao, T., Khan, M., Wang, J., Ji, X., Li, H., LiU, W. \& Shang, Y. (2016). Preparation of $\mathrm{C} / \mathrm{C}-\mathrm{SiC}$ composite by low temperature compression molding-liquid silicon infiltration and its application in automobile brake. Ceramics International 42, 1057-1062.

Yang, Z., Ren, W., Sharma, R., McDonald, S., Mostafavi, M., Vertyagina, Y. \& Marrow, T. J. (2017). In-situ X-ray computed tomography characterisation of 3D fracture evolution and image-based numerical homogenisation of concrete. Cement and Concrete Composites 75, 7483.

Zhang, D., Chen, L., Sun, Y. \& WANG, X. (2015). Transverse tensile damage behaviors of threedimensional five-directional braided composites by meso-scale finite element approach. Journal of Reinforced Plastics and Composites 34, 1202-1220.

Zhou, X., Zhu, D., XIE, Q., Luo, F. \& Zhou, W. (2012). Friction and wear properties of C/C-SiC braking composites. Ceramics International 38, 2467-2473. 


\section{Figure Legends}

Figure 1: Microstructures and orientations for a) longitudinal and b) transverse specimens (loaded in compression along $z$-axis)

Figure 2: Visualizations of the composite material microstructure: a) tomograph cross-section; b) segmentation to identify pores, matrix and fiber tows; c) 3D pore visualization (porosity $3.5 \%$ by volume); d) matrix visualization (matrix $37.8 \%$ by volume); area fractions of pores, matrix and fibers in e) TW; f) LW; and g) LT planes with distance in the orthogonal direction.

Figure 3: Load-crosshead displacement traces from the in situ experiments, with tomographic scan points identified: a) longitudinal compression test; b) transverse compression test.

Figure 4: Visualization of fracture paths: a) Volume rendering of longitudinal test (compression parallel to L) with b) TL and c) LW cross-sections; d) volume rendering of transverse test (compression parallel to T) with e) TL and f) LW cross-sections.

Figure 5: Damage development in the longitudinal test, observed in the same TW plane at a) $20 \mathrm{~N}$ and b) $5000 \mathrm{~N}$; the highlighted regions at $5000 \mathrm{~N}$ are magnified in c) and d). See Figure 6 for numbering.

Figure 6: 3D visualization of crack development in fiber bundle 1 (identified in Figure 5c) with increasing load: a) $20 \mathrm{~N}$ to e) $5000 \mathrm{~N}$ in the longitudinal compressed specimen.

Figure 7: 3D visualization of crack development in fiber bundles 2 to 4 (identified in Figure 5c) with increasing load: a) $20 \mathrm{~N}$ to d) $5000 \mathrm{~N}$ in the longitudinal compressed specimen. 
Figure 8: Damage development in the transverse compressed specimen (TW plane, mid-section). Regions a) to d) are observed under load, and are identified by the dotted box in e), which was observed unloaded, after failure. Five fiber bundles are labeled within a region of interest (dashed box) for reference in Figure 9.

Figure 9: 3D visualization of crack development in fiber bundles 1 to 5 (identified in Figure 8d) with increasing load: a) $20 \mathrm{~N}$; b) $1500 \mathrm{~N}$; and c) $2000 \mathrm{~N}$ in the transverse compressed specimen.

Figure 10: Displacement field maps and tomographs (loaded) for the longitudinal compressed specimen at $5000 \mathrm{~N}$ (a to d); and the transverse compressed specimen at $2500 \mathrm{~N}$ (e to h). The displacements (orthogonal components $d x, d y$ and $d z$, in $\mathrm{mm}$ ) are relative to the circled origin in the reference image.

Figure 11: a) Average strains, measured by digital volume correlation, as a function of load for longitudinal compression and transverse compression; the changes of b) modulus, c) orthogonal strain and d) sample volume with increasing axial strain.

Figure 12: Longitudinally compressed specimen: Comparison of a) a tomograph cross-section (at a height $\mathrm{z}=1.27 \mathrm{~mm}$ within the DVC-analysed volume, measured from the lower surface) with $b$ ) visualization of the measured maximum principle strain, for a TW section of the longitudinally compressed specimen, observed at $5000 \mathrm{~N}$; c) variation of compressive axial strain across the specimen (average variation with position in $y$-direction) as a function of applied load. Points mark the average strains.

Figure 13: 3D visualizations of the development of the maximum principle strain field, with compressive load, measured by digital volume correlation for the longitudinal compression (a-d) and transverse compression (e-g) specimens. 


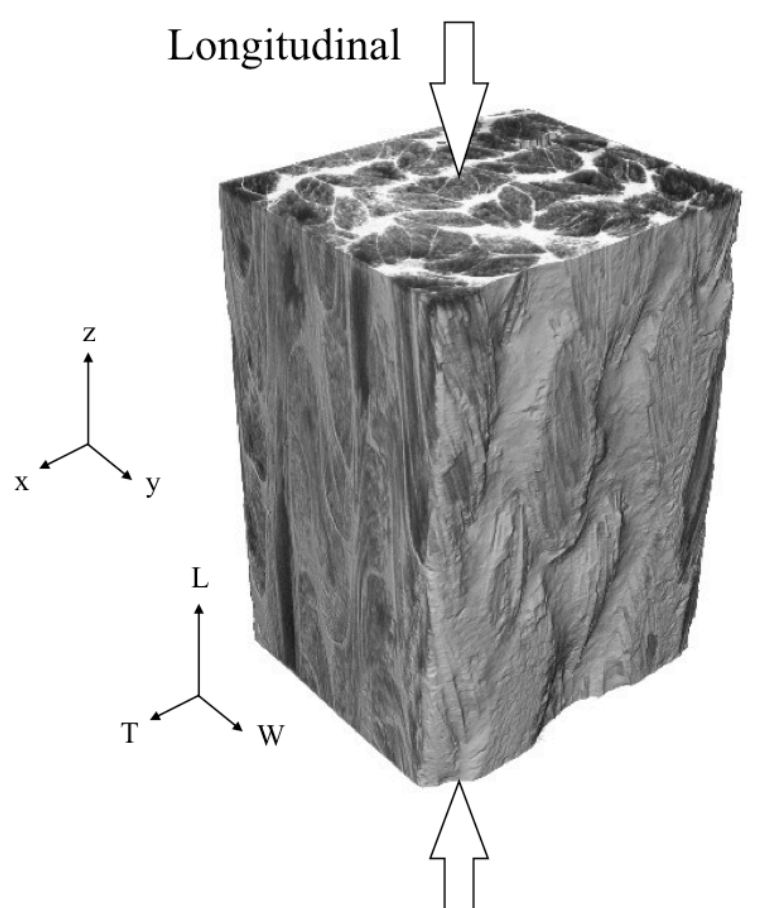

a)

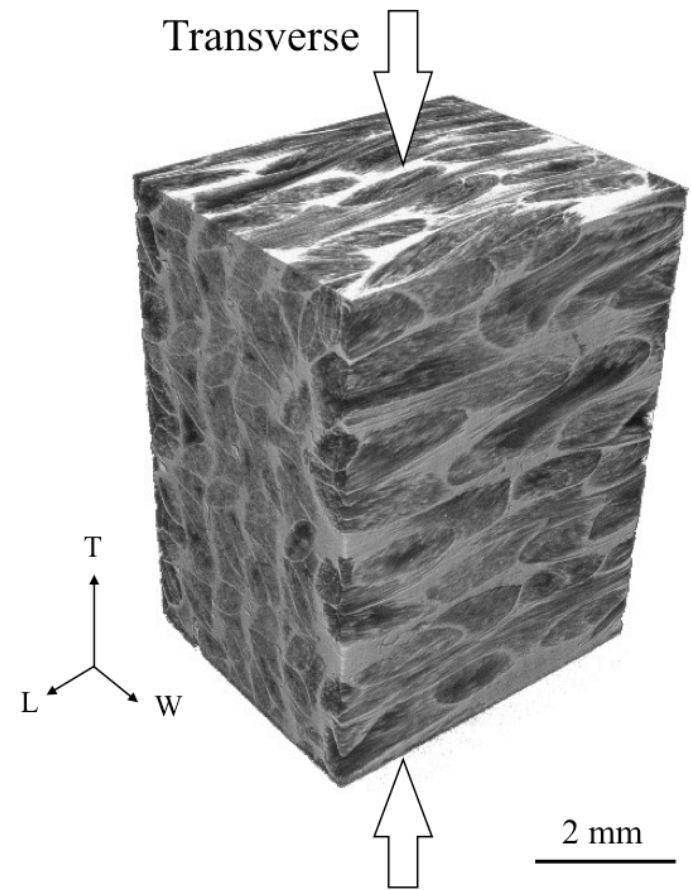

b) 

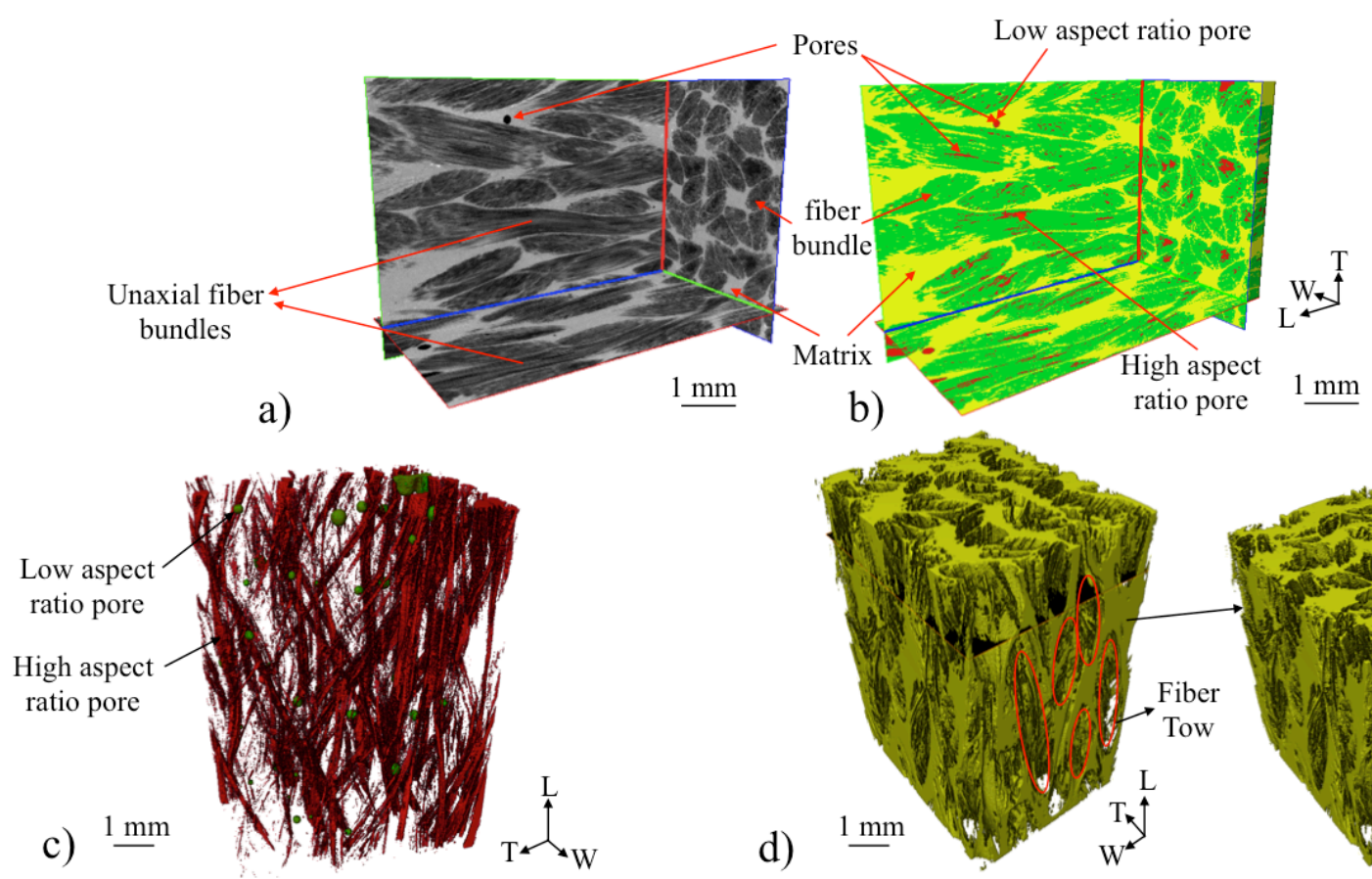

d)
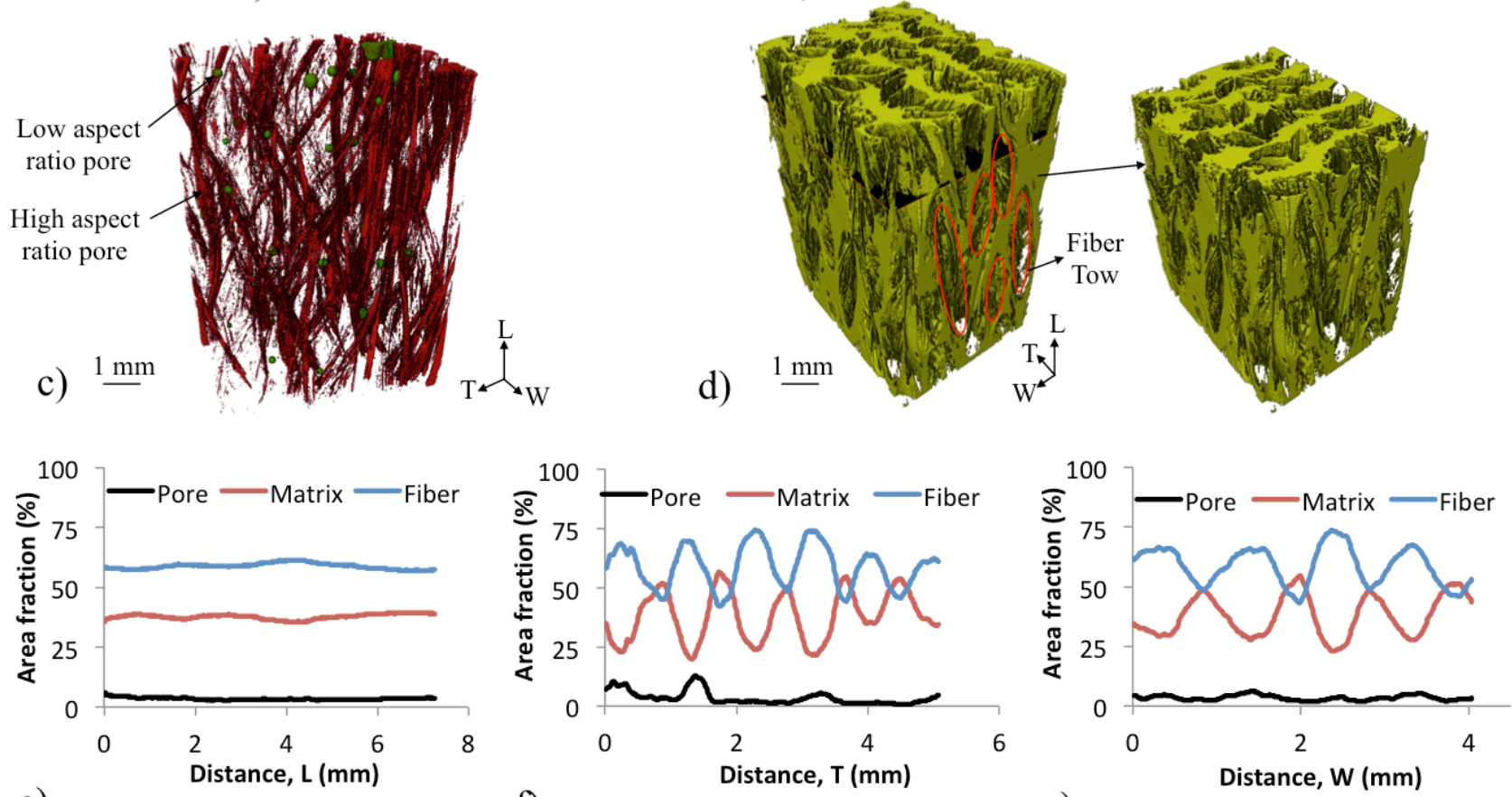

e)

f)

g) 

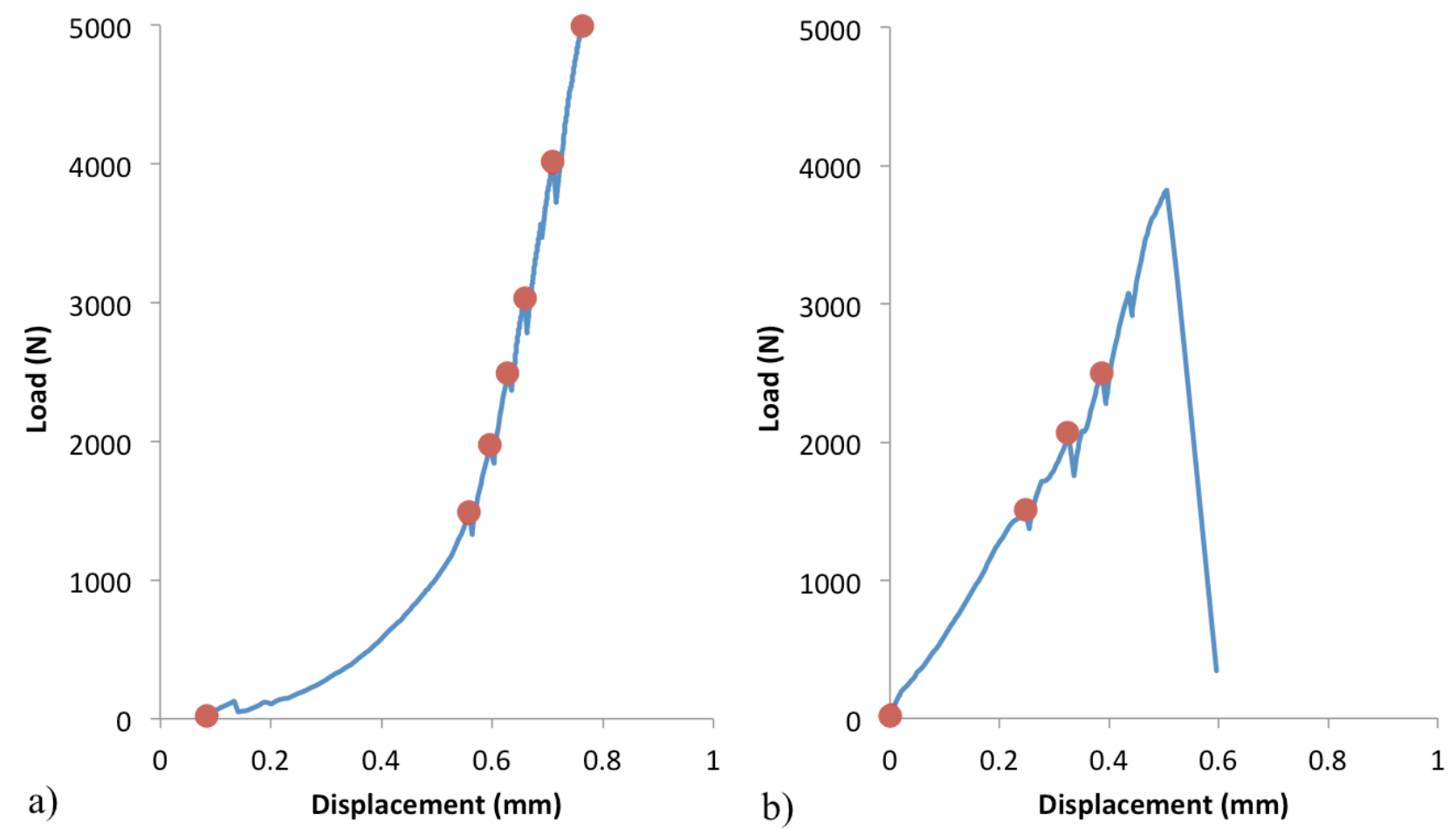


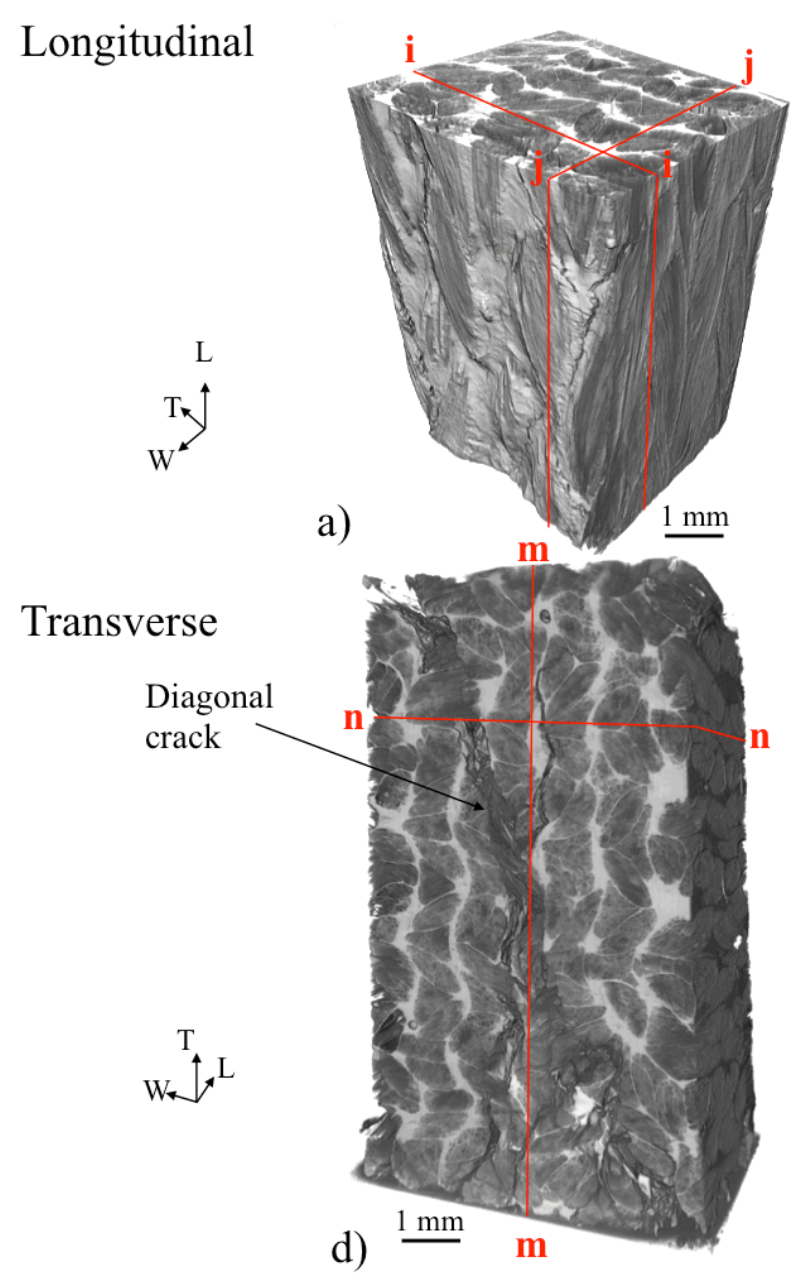

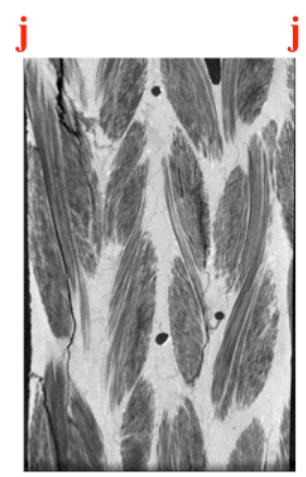

b)

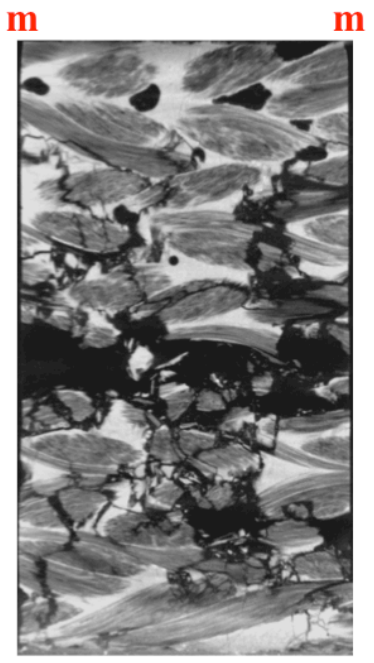

e)

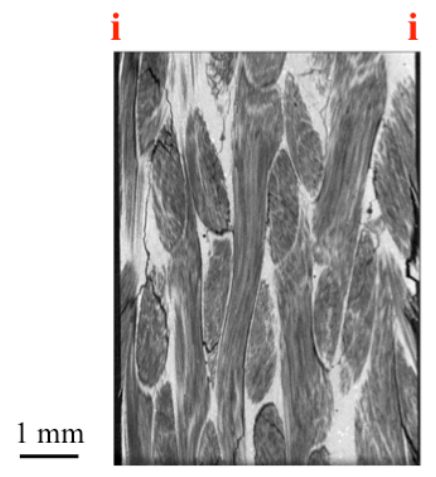

c)

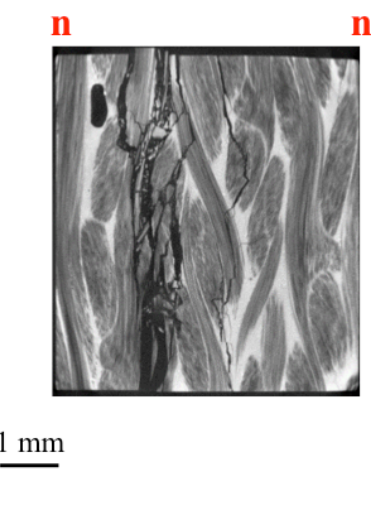

f) 


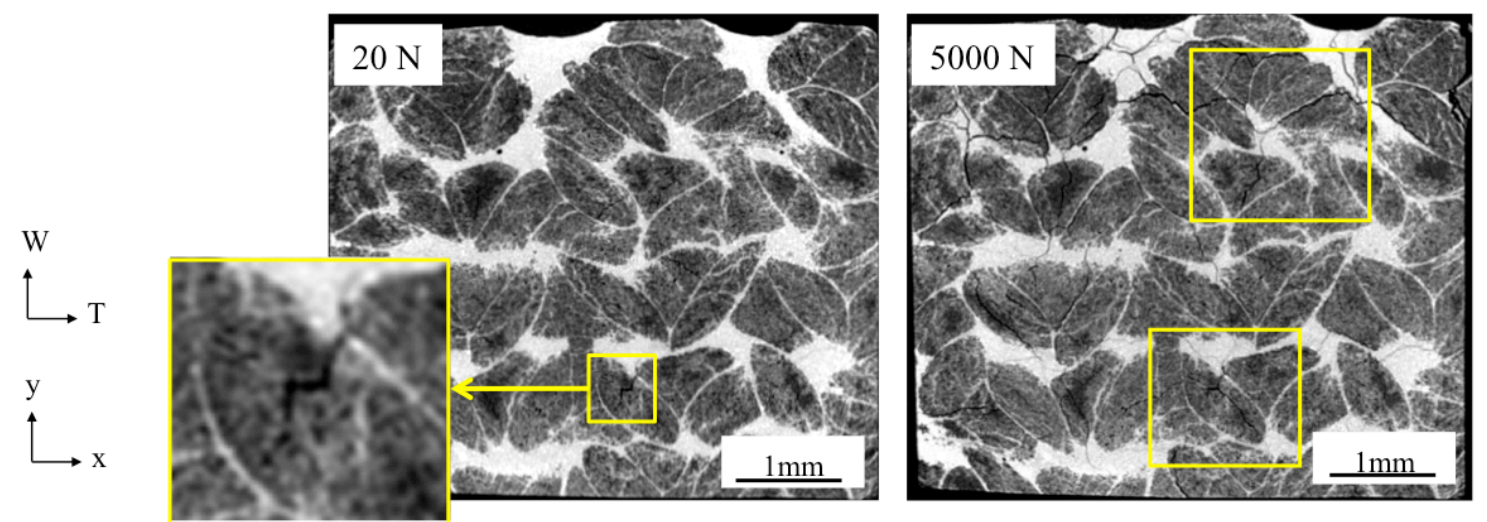

a)

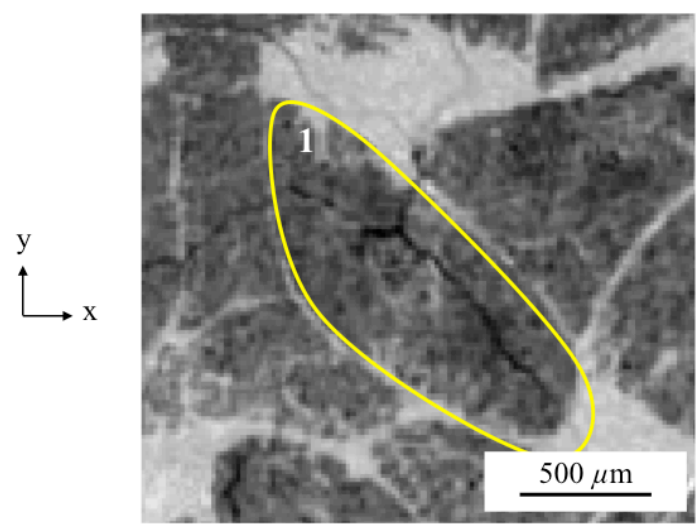

b)

c)

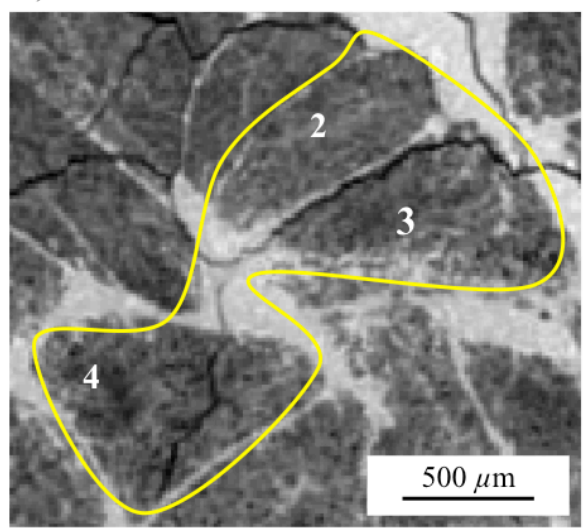

d) 


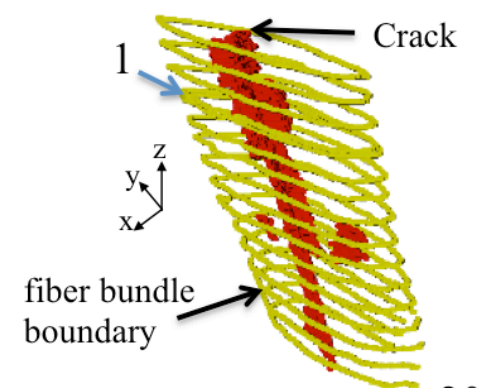

a)

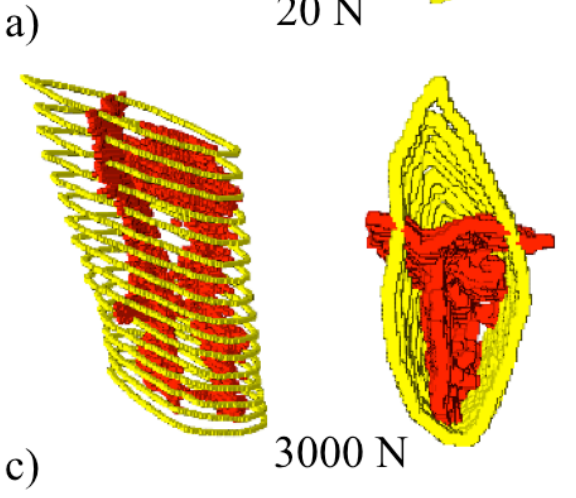

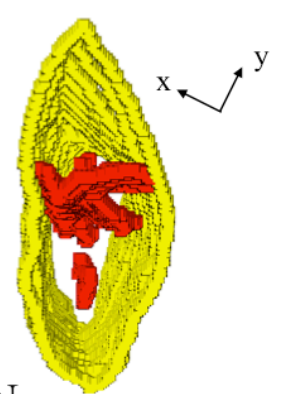

$500 \mu \mathrm{m}$

b)

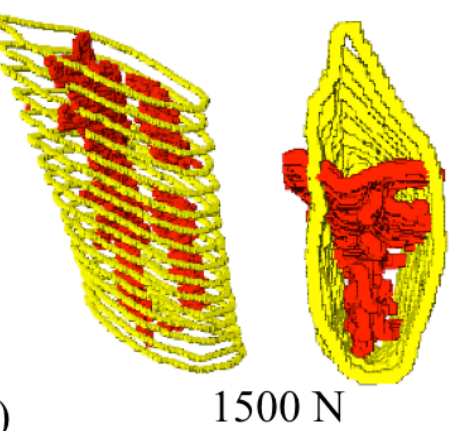

d)

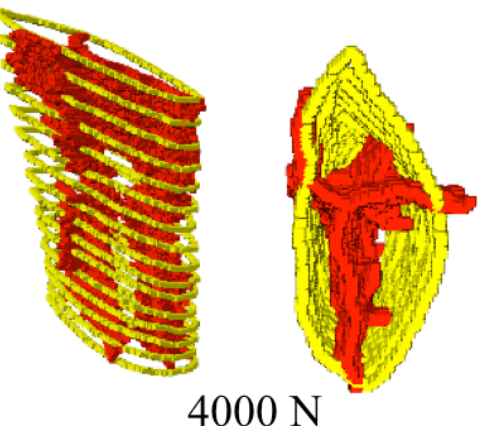

e)

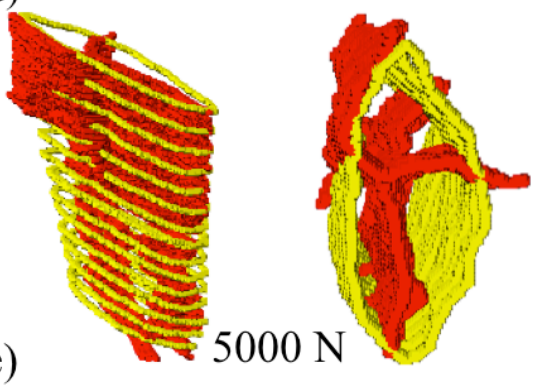




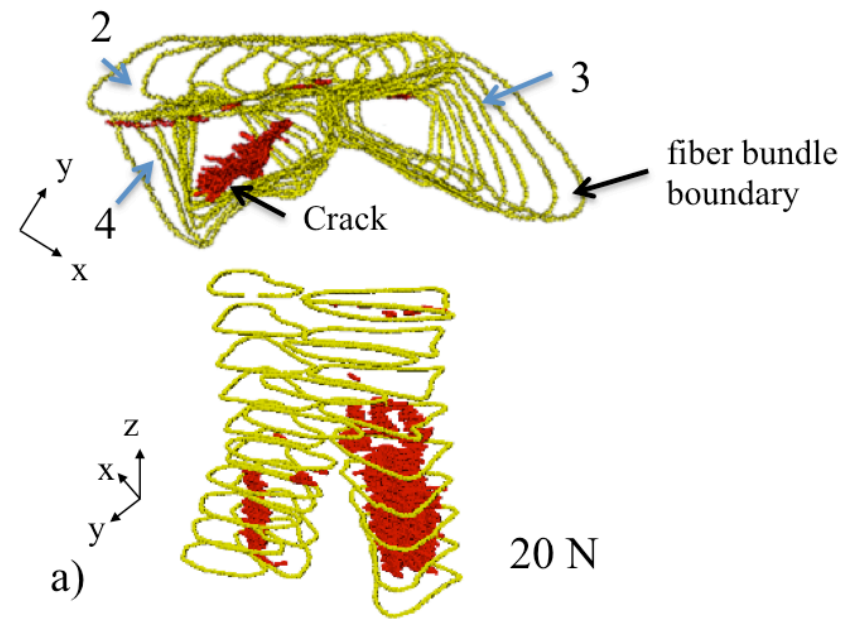

b)
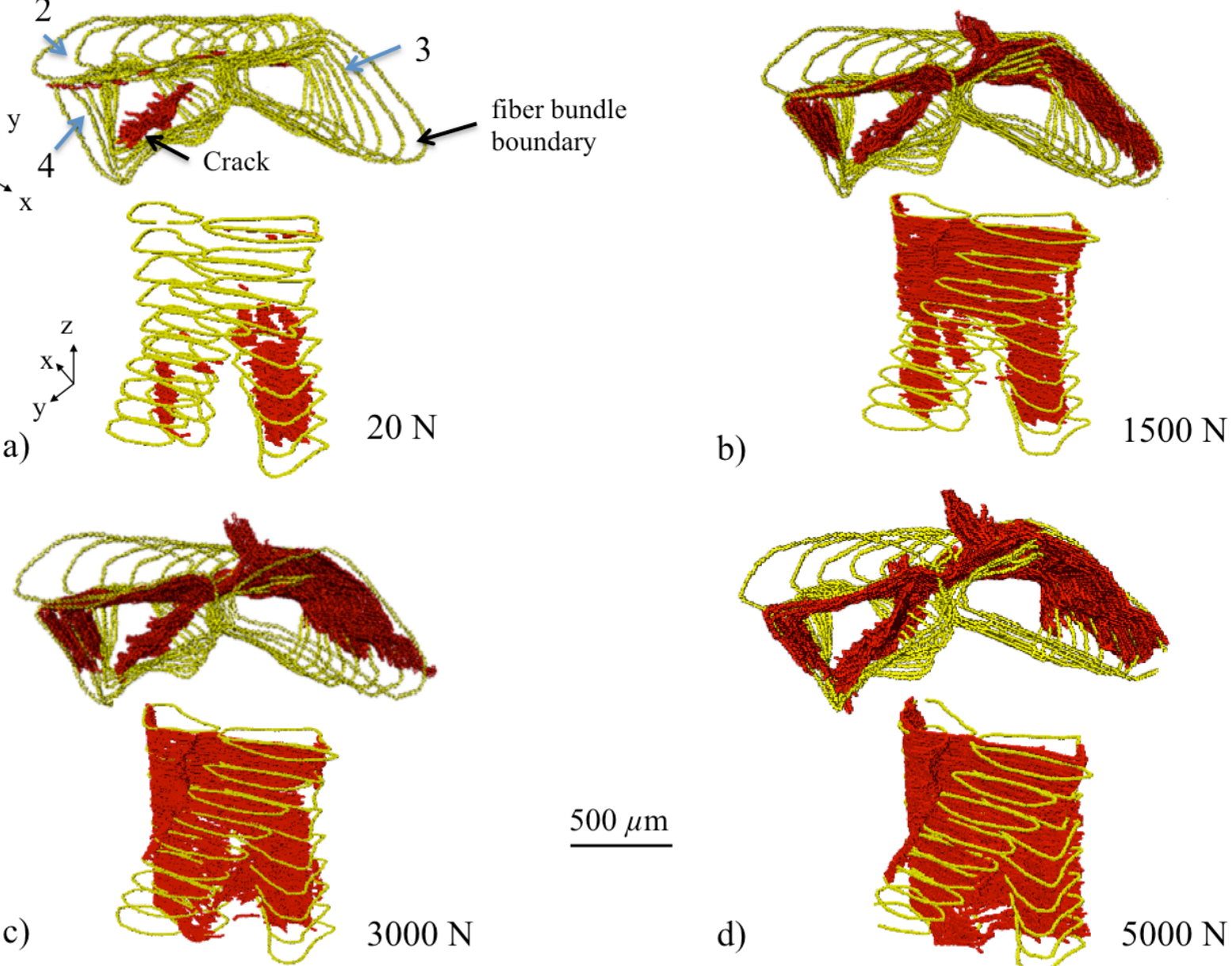

$500 \mu \mathrm{m}$

d)

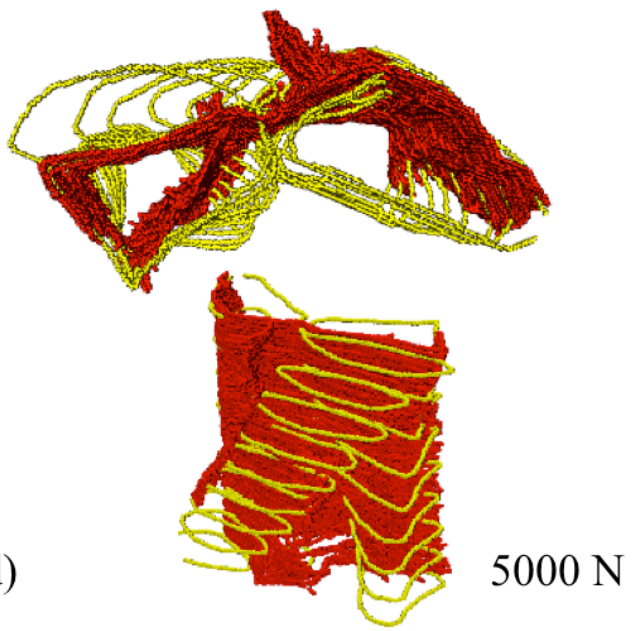


a)

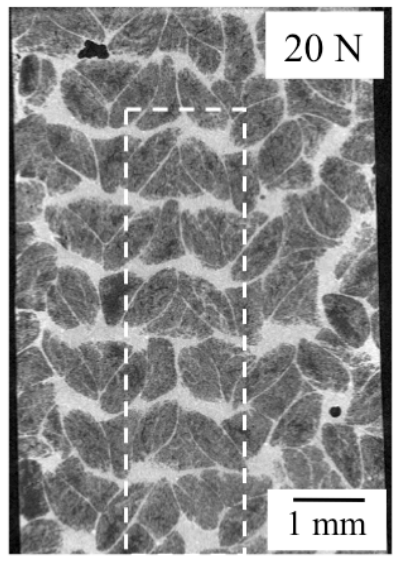

b)

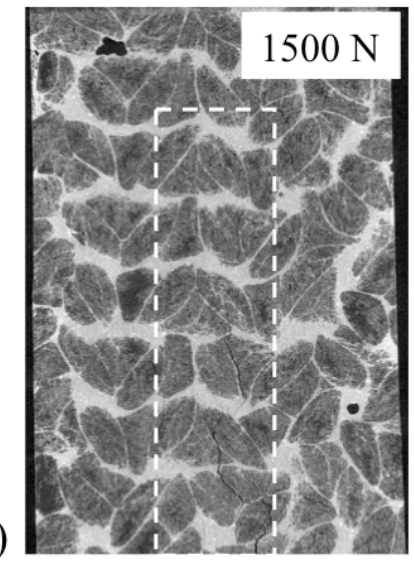

c)

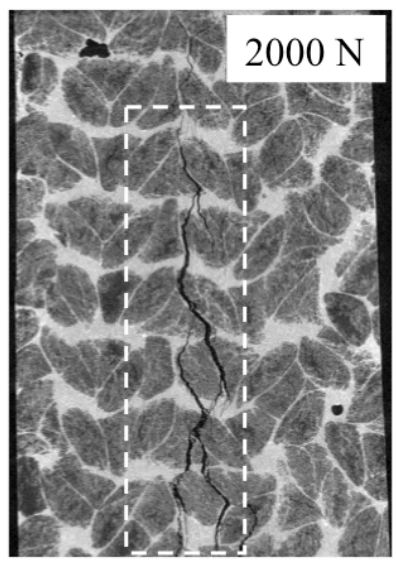

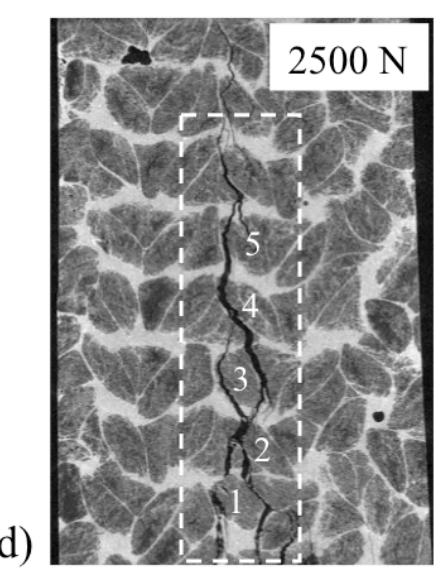

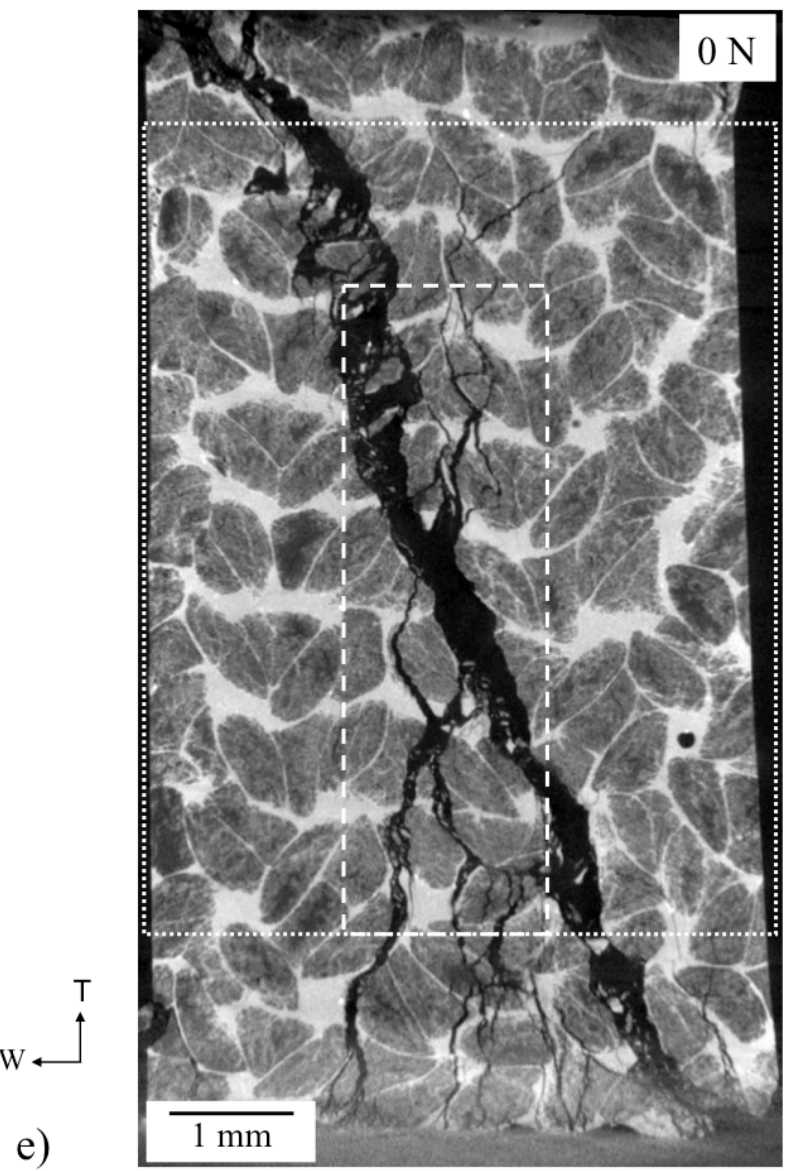



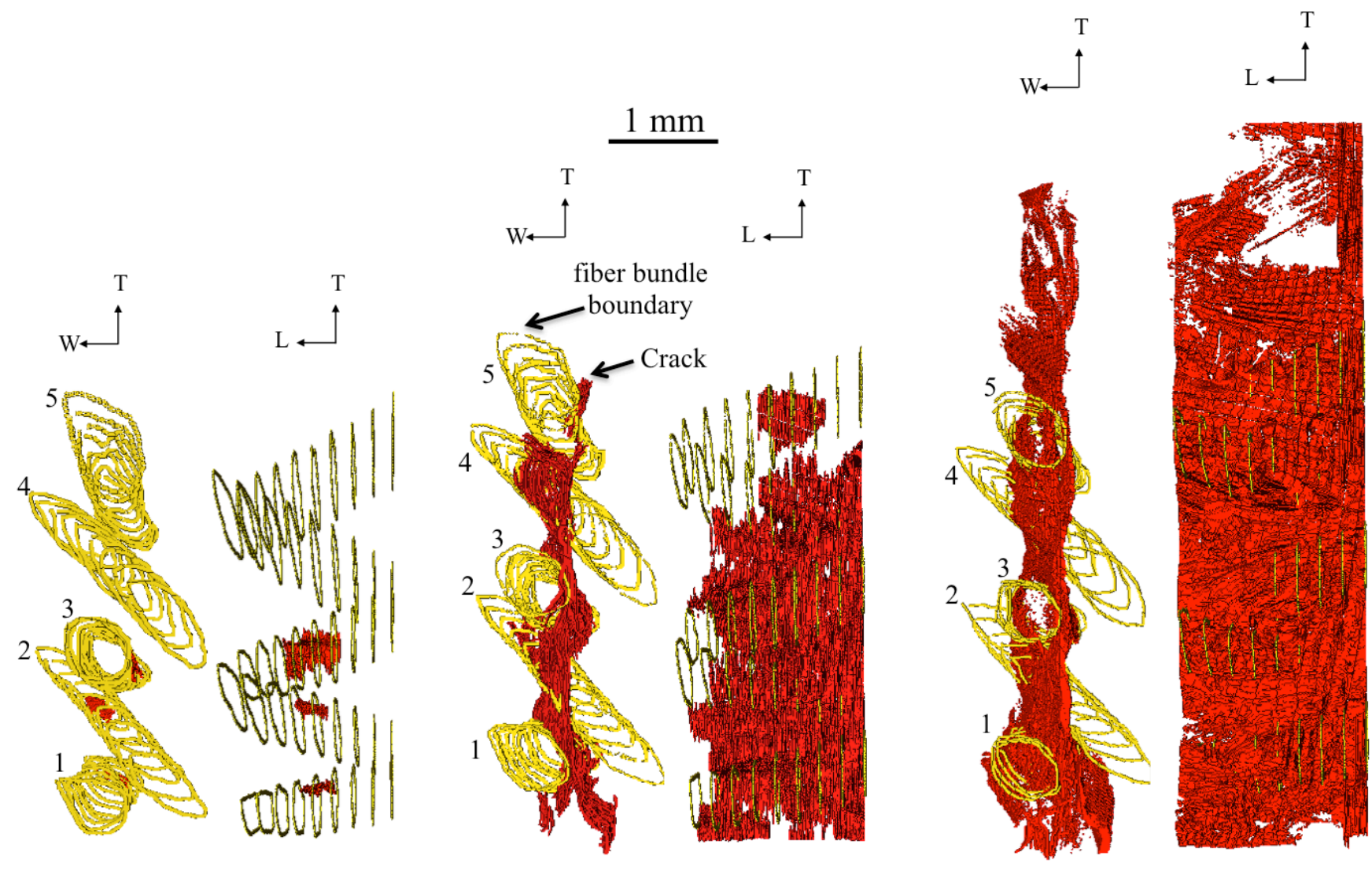

a)

b)

c) 


\section{Longitudinal}

a)

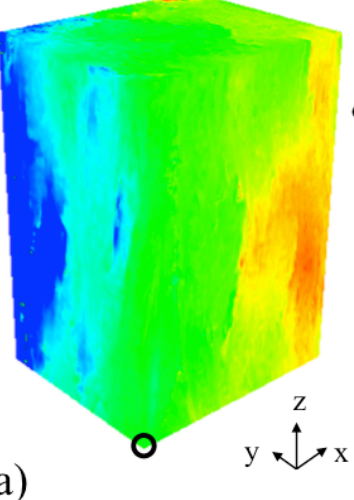

Transverse

e)

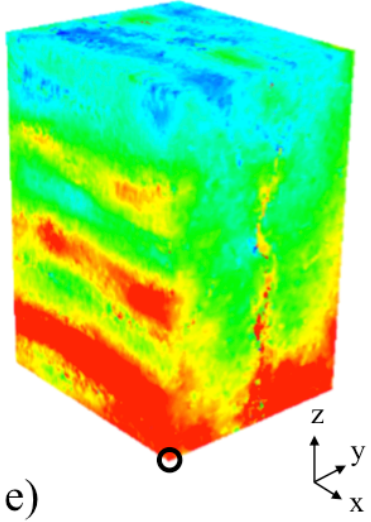

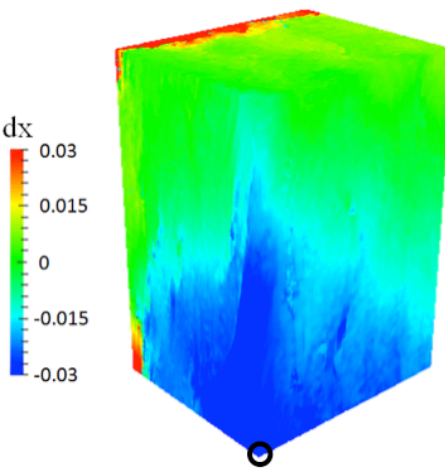

b)

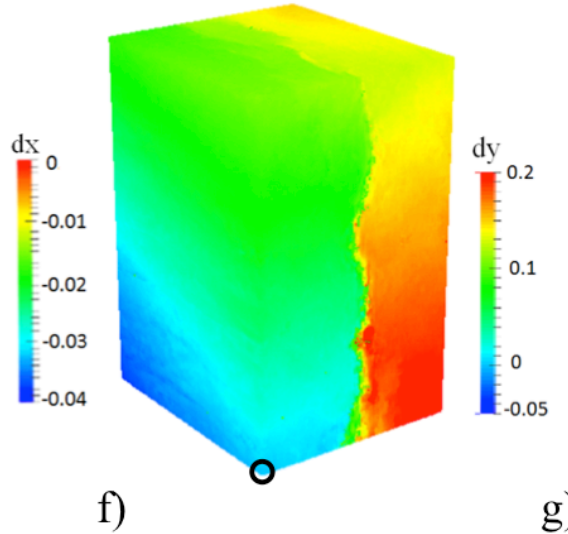

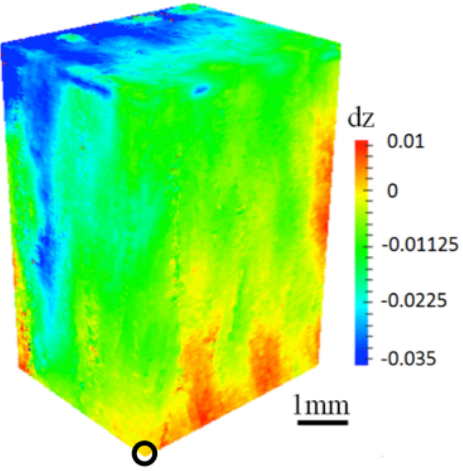

c)

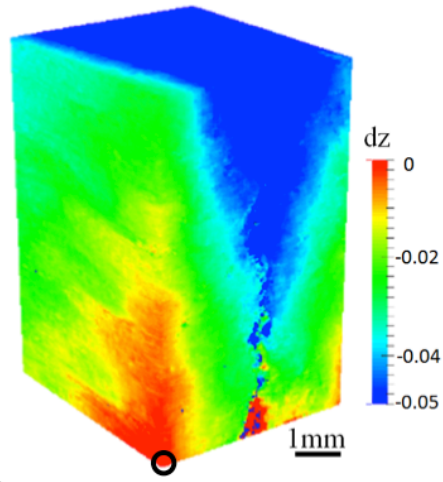

g)

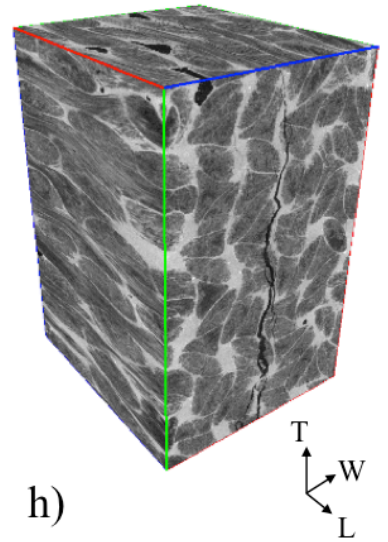



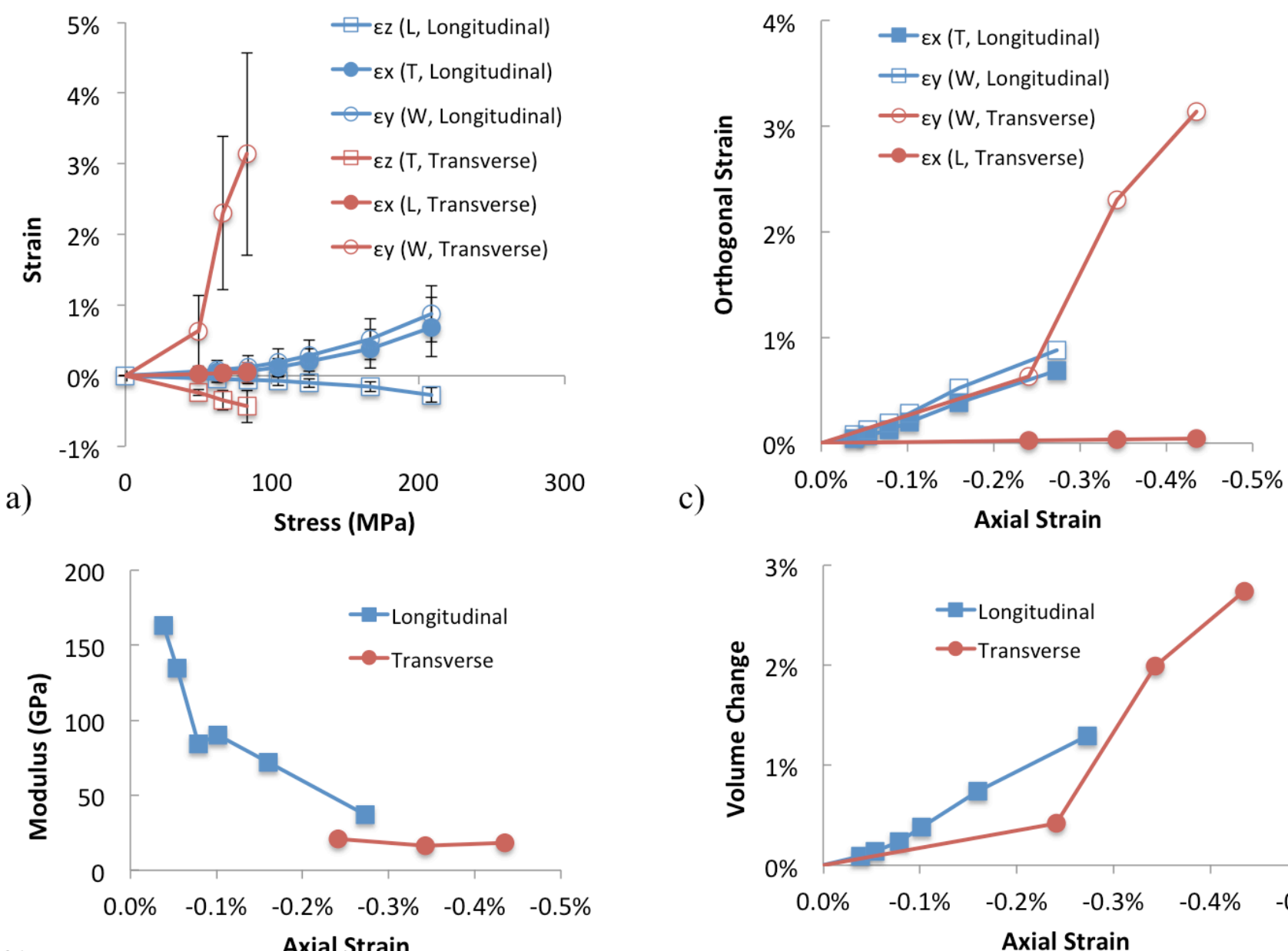

b)

Axial Strain

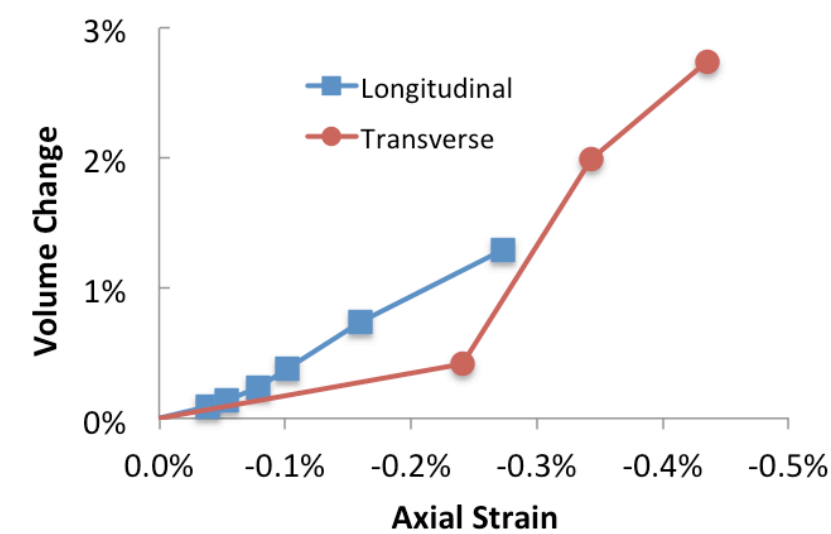

d) 


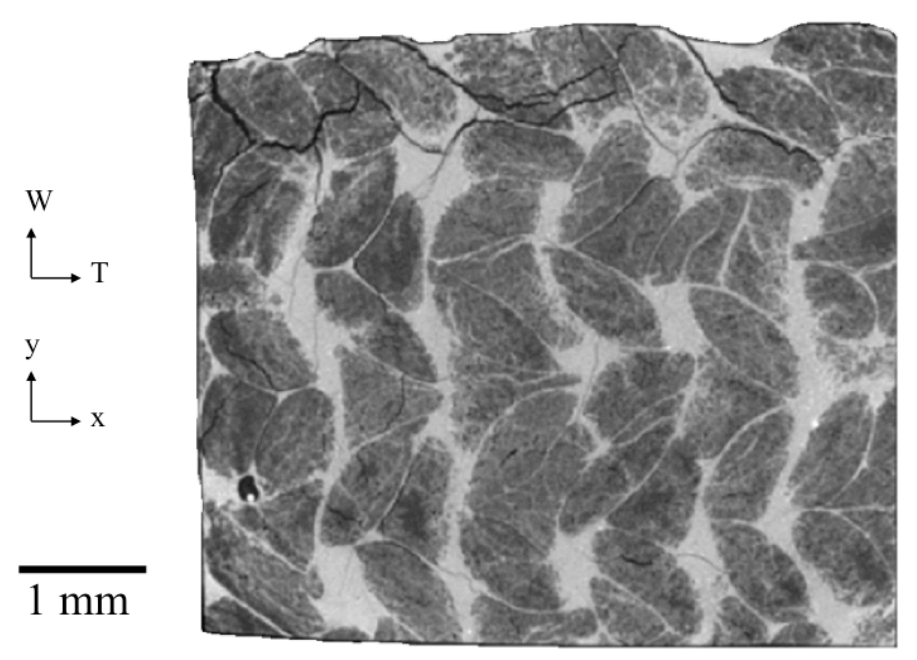

a)

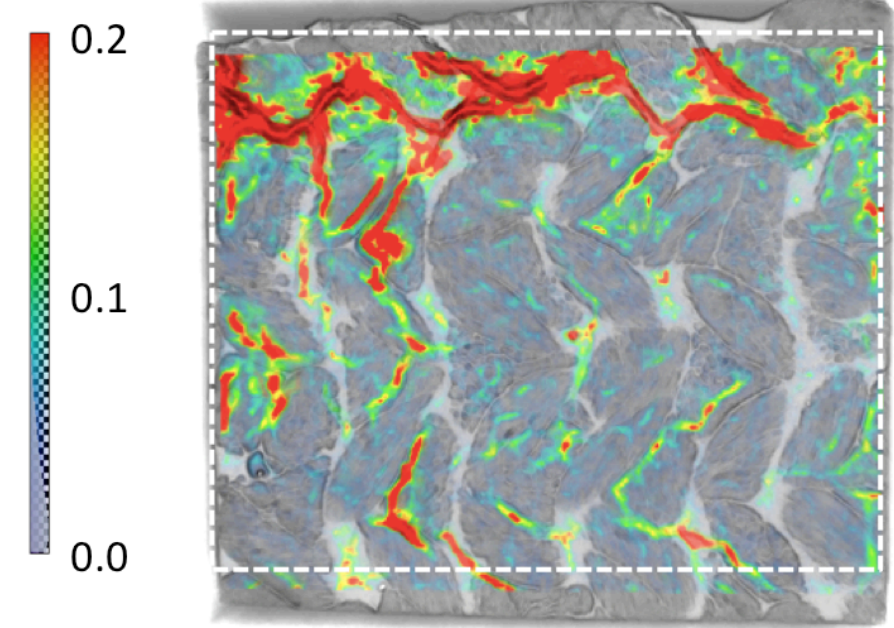

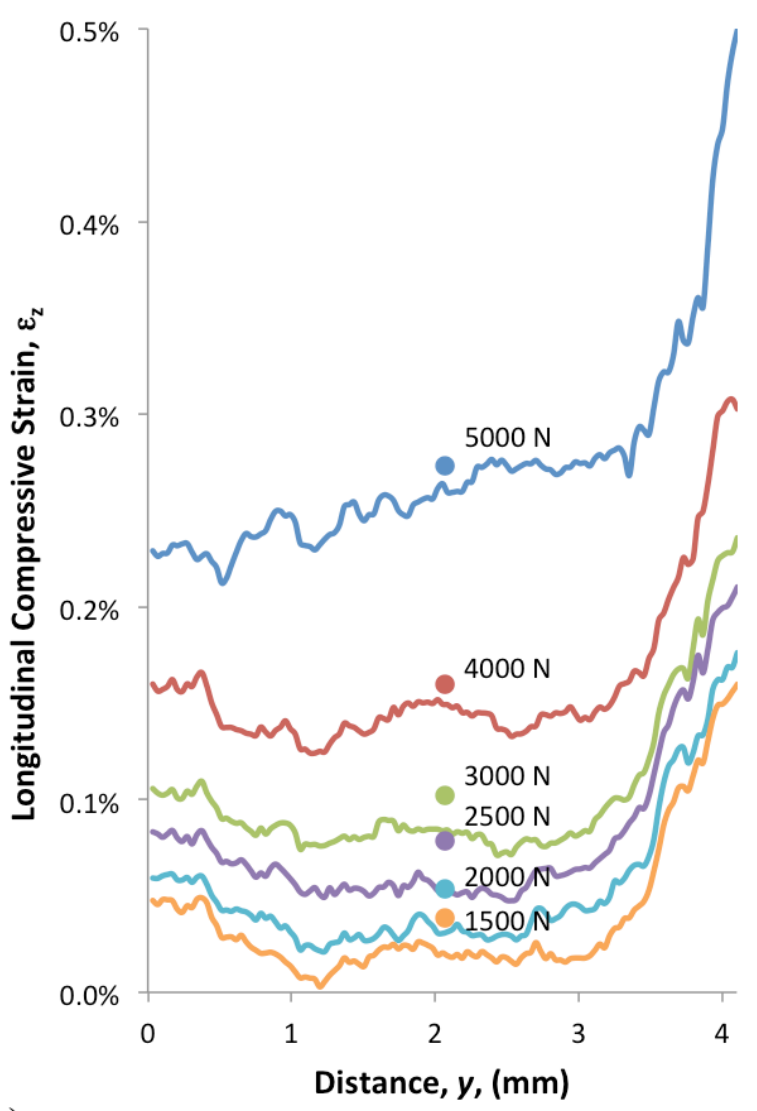

c) 


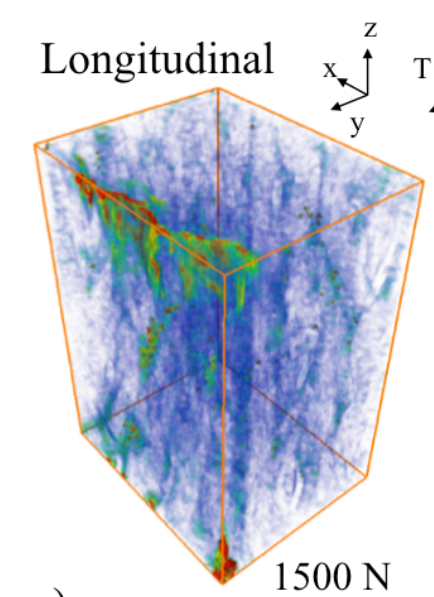

a)

\section{Transverse}

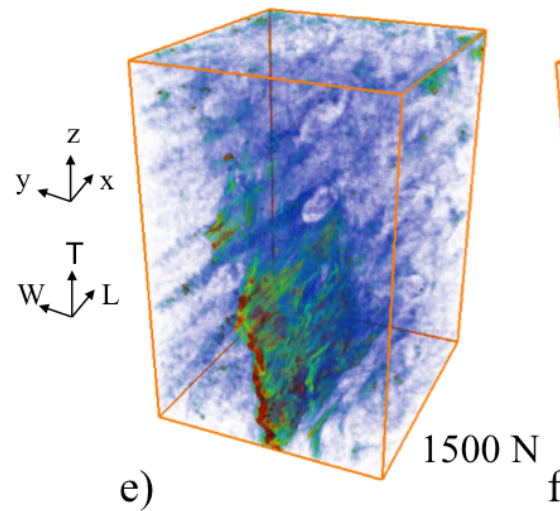

e)

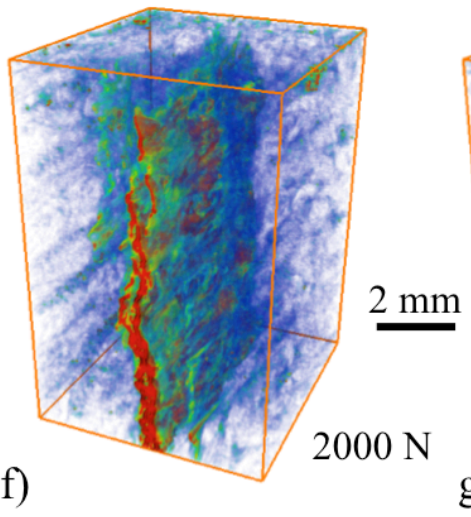

b)

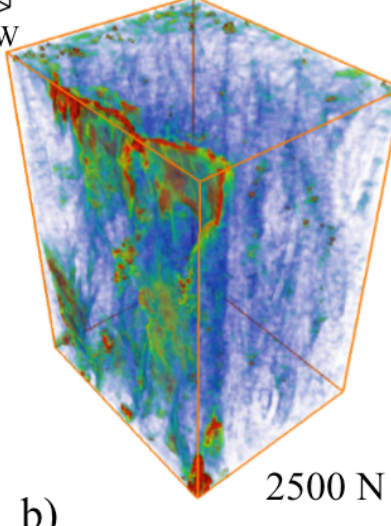

c)
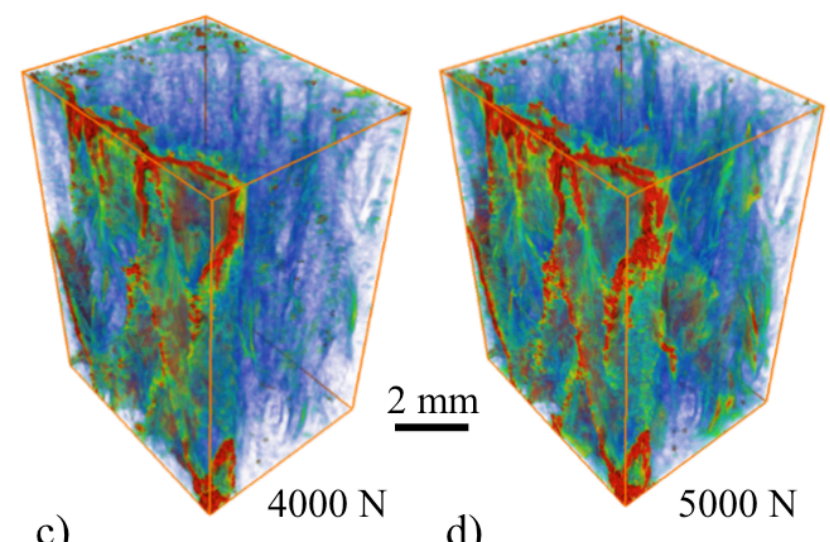

0.2

0.1

d)
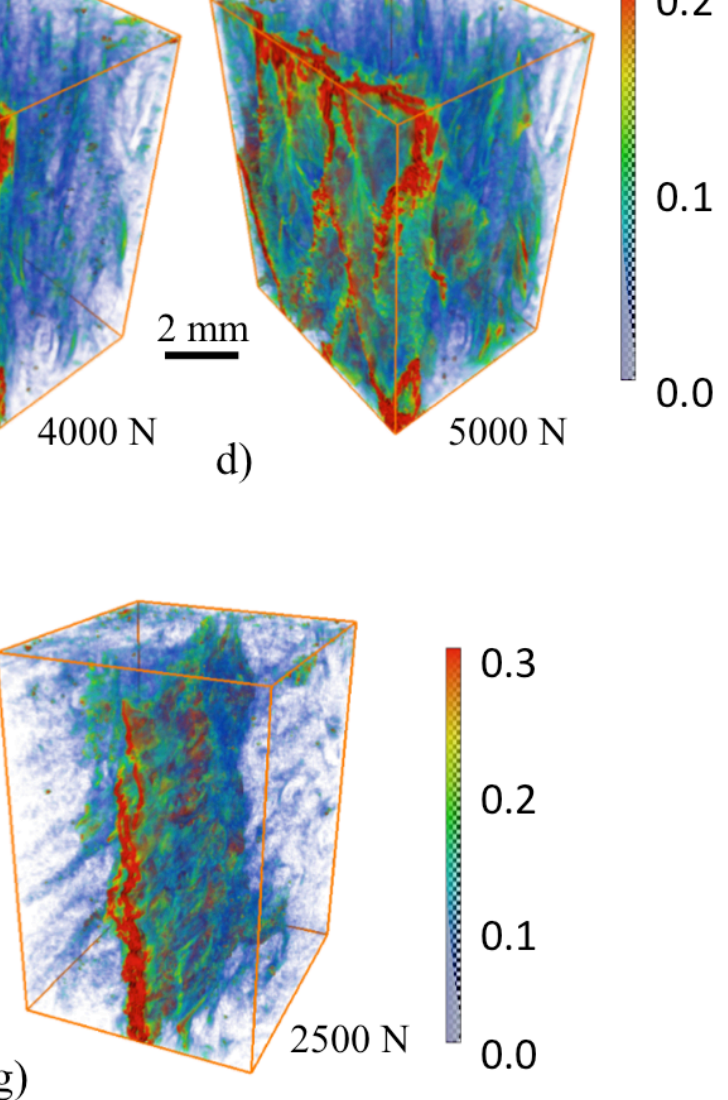


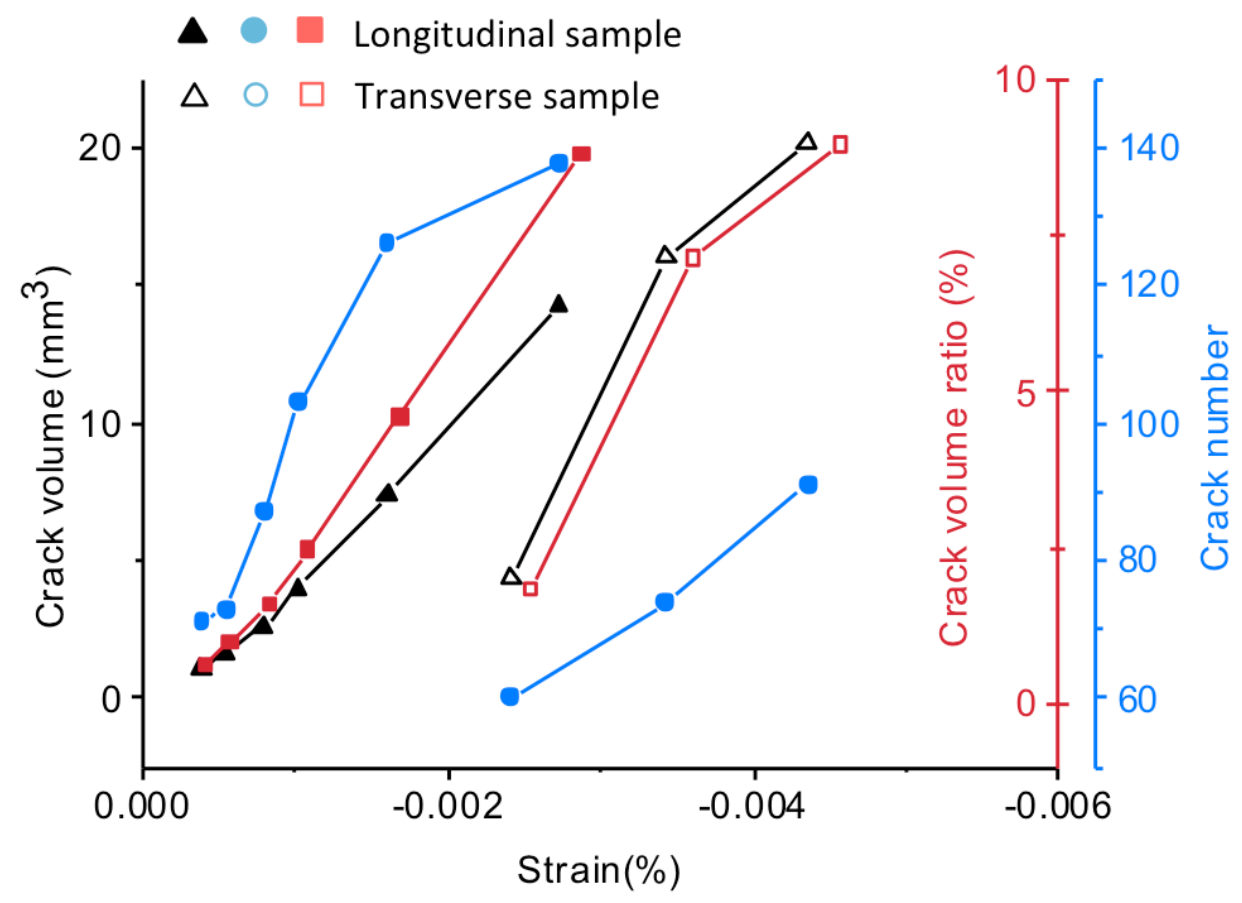

